\title{
LOS DERECHOS DEL NIÑO EN CHILE: UNA APROXIMACIÓN HISTÓRICA, 1910-1930²
}

\begin{abstract}
En este artículo se muestra la temprana influencia que ejerció en Chile la idea de los "derechos del niño", entre 1900 y 1930, a través de la circulación de sucesivos textos. El contenido de estos fue bastante variable, fluctuando entre los que se limitaban a establecer la protección física del niño y los que reconocían una mayor autonomía de este frente al adulto. Aunque desprovistas de una doctrina que las sustentara, estas declaraciones de derechos del niño lograron cierto impacto en el ambiente intelectual de la época, tanto de aceptación como de rechazo, lo que se expresó en diversas políticas públicas que se detallan en este artículo.
\end{abstract}

Palabras clave: Derechos del niño, infancia, protección, protagonismo infantil.

This article demonstrates that there was an early influence of children rights ideas in Chile between 1900 and 1930. These ideas were expressed through declarations that circulated in Chilean society and were variable. They ranged from those that demanded physical protection for children to those that pushed for a recognition of highest levels of autonomy of them. Even though these declarations did not have a solid supporting doctrine, they generated an impact in intellectual circles at the beginning of the twentieth century. The different opinions elaborated about children rights -opposing or supporting them- gave room to the establishment of public policies about the issue, which are presented in this work.

Key words: Rights of the child, infancy, protection of the child, infantile protagonism.

\section{INTRODUCCIÓN}

El debate actual sobre los derechos del niño ha considerado pocas veces la trayectoria histórica del tema, así como las tensiones que han aflorado entre los distintos enfoques que coexisten en su interior, y sus efectos en la elaboración de políticas públicas y nuevas experiencias en el ámbito privado.

En este artículo buscamos mostrar una parte de esa trayectoria en el contexto chileno, entre 1900 y 1930 , cuando se comenzaron a divulgar las primeras

\footnotetext{
1 Universidades de Talca, Arcis, Alberto Hurtado y Finis Terrae. Correo electrónico: jorgerojasflores@hotmail.com

2 Este texto se realizó en el marco del proyecto "Experiencias de niños y concepciones de la infancia. Chile en los años 20", Fondecyt N 1040660. Agradezco las referencias bibliográficas que me facilitaron el profesor José María Borrás Llop y su alumna Marta Puig Ávila.
} 
propuestas, y tomó cuerpo un ambiente receptivo a esta incipiente doctrina jurídica, aunque no exento de ciertas resistencias y críticas a los cambios que esto implicaba.

Debido a la difusa y errática presencia del tema, que no logró adquirir real consistencia teórica, mostraremos su desarrollo a través de los textos que se conocieron en el país, los que no siempre provocaron reflexiones. Adicionalmente pasaremos revista al ambiente de recepción y rechazo que estas ideas alcanzaron, en las diversas áreas relacionadas con la infancia.

\section{LOS DERECHOS DEL NIÑO}

La doctrina de los Derechos del Niño tiene un largo recorrido en Europa occidental y Estados Unidos, así como en el ámbito latinoamericano. Lejos de ser una propuesta reciente, sus raíces se remontan al siglo XIX y no deja de sorprender la trayectoria que ha tenido la idea y su divulgación, aunque su contenido mismo haya sido bastante variable y zigzagueante ${ }^{3}$.

En nuestro continente, la sensibilidad a favor de los niños se fortaleció notablemente durante la segunda mitad del siglo XIX. A comienzos del siglo XX ya estaba asentada la idea, cuando menos a nivel institucional, de que a los niños se les debía asegurar un cierto nivel de bienestar material y espiritual. Esto no siempre significó un reconocimiento de derechos en un sentido estricto, sino muchas veces el desarrollo de un sentimiento de compasión y piedad. Sin embargo, la idea de que los niños requerían de cierta protección por su propia condición vulnerable y frágil pronto se relacionó con el concepto de "derechos". La influencia cultural europea, y luego norteamericana, fue clave para la difusión de este enfoque.

Las primeras referencias a los derechos del niño son atribuidas a varios autores. El revolucionario francés Jules Vallès (1832-1885), por ejemplo, estuvo entre los primeros en formular la defensa de los derechos del niño. Su obra autobiográfica El niño (1879) fue una abierta denuncia hacia los métodos coercitivos aplicados por la cultura burguesa y se sumó a otras obras literarias de la época igualmente sensibles al tema, como la de Charles Dickens ${ }^{4}$.

Pero fue en Estados Unidos donde se produjo, por primera vez, un mayor desarrollo del concepto. La escritora y educadora Kate D. Wiggin (1856-1923) publicó en 1892 Children's Rights, donde no solo planteaba la necesidad de defender los derechos del niño, sino otorgaba un contenido específico al con-

3 Una reconstrucción del concepto de derechos del niño, desde fines del siglo XIX hasta fines del XX, puede consultarse en el texto de Philip E. Veerman, The Rights of the Child and the Changing Image of Childhood The Netherlands, International Studies in Human Rights, vol. 18, Martinus Nijhoff Publishers, 1992. Su énfasis está puesto en el ambiente anglosajón europeo.

4 A través del pequeño protagonista del libro, enfrentado a una conflictiva relación con sus padres, Jules Vallès planteó su propia declaración de intenciones: “defenderé los derechos de los niños al igual que otros defienden los derechos del hombre" ("je défendrai les Droits de l'Enfant comme d'autres les Droits de l'Homme”, cap. XXV). Esta frase es citada como una de las precursoras en el tema de los derechos del niño. 
cepto. En su opinión, el derecho no era equivalente, sino muchas veces opuesto, al concepto de privilegio o indulgencia. Bien podían otorgarse muchos privilegios a los niños, sin que se respetaran sus derechos. Esto se producía cuando subsistía la creencia de que los niños pertenecían a sus padres, quienes hacían uso de un poder ilimitado sobre ellos. Según la autora, los niños -en cuanto seres humanos- se pertenecen a sí mismos y uno de sus derechos inalienables es a tener infancia. En la práctica, esto se ve limitado cuando los adultos moldean su conducta según sus criterios, sin permitir que tengan un espacio propio, adecuado a sus gustos y necesidades. Por ejemplo, el exceso de celo materno negaba el elemental derecho de los niños a "andar sucio". Aunque el texto no fue traducido al castellano, fue conocido en Chile, así como algunos de sus cuentos para niños ${ }^{5}$.

Poco después, Ellen Key (1849-1926) formularía ideas convergentes en su obra El Siglo de los Niños (1900), que alcanzó notable difusión en el mundo occidental, a través de su traducción a varios idiomas. Aunque su propósito central era exponer la necesidad de cambiar la educación predominante hasta entonces, en sus páginas planteó algunas ideas que fortalecerían la noción de derechos del niño. Por ejemplo, defendió el "derecho de los hijos" a tener una familia unida por el amor y la armonía, es decir, una "unión libre" y no una convivencia forzada por la discordia y el convencionalismo social. También reconocía el derecho de los niños a nacer de madres sanas y robustas, preocupadas de su formación; de lo contrario, era preferible renunciar a la maternidad. En la educación no debían imponerse castigos, había que respetar la personalidad de los niños, permitiendo que vivieran a su manera, no obligados por un modelo impuesto por los adultos 6 .

La nueva pedagogía que se gestaba en aquellos años tuvo en Ellen Key a una de sus primeras exponentes. Por diversos canales, una nueva concepción de la infancia se fue irradiando, entre educadores, sicólogos y pediatras. Varios de ellos incorporaron en sus enfoques la idea de los derechos del niño, aunque no siempre los formularon en forma explícita, ni entendieron la reforma pedagógica en un mismo sentido. John Dewey (1859-1952), en Estados Unidos, fue un claro divulgador de una ciudadanía activa en las escuelas, aunque su aporte teórico no se concentró en conceptualizar el tema de los derechos del niño ${ }^{7}$. Maria Montessori (1870-1952) aplicó un método pedagógico que reconocía la peculiaridad e individualidad del niño, así como el desarrollo diferenciado de sus capacidades y

5 Kate Douglas Wiggin, Children's rights. A book of nursery logic Boston-New York, Houghton Mifflin Co., The Riverside Press Cambridge, 1892. Este texto está en la Biblioteca Nacional, así como otras obras literarias de la autora.

${ }^{6}$ Recordemos que Key se distanciaba de la moral católica y se mostraba favorable al divorcio. Hubo una edición española: Ellen Key, El siglo de los niños (Estudios) 2 tomos, Barcelona, Biblioteca Sociológica Internacional, Imprenta de Henrich y Comp. en C. Editores, 1906.

7 Entre sus obras destacan: My Pedagogic Creed (1897); The School and Society (1899); Ethics (1908); How We Think (1910); Democracy and Education (1916); Essays in Experimental Logic (1916); Reconstruction in Philosophy (1920); Human Nature and Conduct (1922); Experience and Nature (1925); The Public and Its Problems (1927); The Quest for Certainty (1929). 
su natural tendencia a disfrutar del proceso de aprendizaje ${ }^{8}$. Paul Robin (18371912) y Sébastien Faure (1858-1942) no solo concibieron una pedagogía libertaria, sino que la aplicaron en instituciones que administraron, donde alcanzó su máxima expresión el protagonismo de los niños, en una perspectiva democratizadora y emancipadora del individuo. En España, Francisco Ferrer (1859-1909) también se encauzó dentro del enfoque libertario. En su propuesta se incluyó el desarrollo de la iniciativa del niño y su sentido crítico, relaciones igualitarias, solidarias y cooperativas, así como respeto a la libertad de expresión ${ }^{9}$. En ese mismo país, uno de los divulgadores de la pedagogía activa fue Fernando Sainz, quien publicó en 1929 un libro titulado Los derechos del niño ${ }^{10}$. En Polonia, Janusz Korczak (seudónimo de Henryk Goldszmit), un pediatra y escritor de cuentos para niños, escribió dos obras donde dejó translúcida su fervorosa defensa de los derechos del niño: How to Love a Child [Cómo amar a un niño] (1919) y The Child's Right to Respect [Para respetar el derecho del niño] (1929). Además de sus escritos, Korczak aplicó una experiencia de autogobierno en un asilo para niños que administró ${ }^{11}$.

El movimiento de la nueva pedagogía también llegó a la Rusia zarista. Tras el estallido de la revolución bolchevique (y antes que se consolidara el stalinismo), aumentó notablemente el fervor por transformar la educación en uno de los pilares constituyentes de la sociedad socialista, donde el niño ocuparía un nuevo estatus. Varias tendencias pedagógicas se disputaron el fértil terreno. A pocos meses de producirse la revolución, en una convención de cultura proletaria (realizada en Moscú, en febrero de 1918), la Asociación para la Educación Libre (Association for Free Education) presentó un borrador de Declaración de Derechos del Niño, que no logró ser aprobada debido a su enfoque excesivamente "individualista". El texto incluía 17 puntos, algunos de ellos bastante innovadores. Por ejemplo, se declaraba que todo niño era dueño de sí mismo y no podía ser considerado propiedad de sus padres, la sociedad ni el Estado (art. 3). Cada niño tenía el derecho a escoger a los educadores más cercanos, y de apartarse de sus padres si estos eran malos educadores (art. 4). Ningún niño podía ser forzado a permanecer en una institución educacional (art. 6). Nadie (incluyendo sus padres, la sociedad ni el Estado) podría forzar a un niño a ser instruido en una religión en particular o a practicar sus ritos. La educación religiosa debía quedar a libre elección del niño (art. 12). Todo niño tenía derecho a crear organizaciones y asociaciones, junto a

8 Entre sus obras: El método Montessori (1912); Antropología pedagógica (1913); Método avanzado Montessori (2 vols., 1917); El método de la pedagogía científica, (1928); Ideas generales sobre mi método (1928); El niño en la Iglesia (1929), La misa explicada a los niños (1932), Paz y educación (1934); El secreto de la infancia (1936), y Manual de pedagogía científica (1936).

9 Jorge Rojas Flores, Moral y prácticas cívicas en los niños chilenos, 1880-1950 (Santiago, Ariadna Ediciones, 2004), 244-246.

10 El libro no hemos podido consultarlo. El título lo obtuvimos del catálogo de la Biblioteca Nacional de España en http://www.bne.es

11 Veerman, The Rights of the Child, 93-110. Una útil biografía es la de Betty Jean Lifton, The King of Children. The Life and Death of Janusz Korczak, disponible en http://korczak.com/Biography/ kap-0.htm También puede consultarse la biografía publicada en Wikipedia: http://en.wikipedia.org/ wiki/Janusz_Korczak 
otros niños o adultos (art. 15). En la medida que sus talentos y habilidades lo permitieran, desde la temprana infancia los niños debían participar en un trabajo educativo en bien de la comunidad, el que no debía impedir su salud física ni su desarrollo espiritual. Esto le permitiría sentirse un miembro activo de la sociedad y constructor de su vida, y no un "parásito"12.

Las ideas expresadas por Wiggin, Key y la Asociación para la Educación Libre anticipaban lo que, con posterioridad, sería la concepción moderna de los derechos del niño, alcanzando a veces un carácter bastante más radical. Sin embargo, por varias décadas, estas ideas no fueron desarrolladas principalmente en esa dirección. Al contrario, prevaleció aquello que Wiggin criticaba, es decir, una protección de la infancia que no llegaba a constituir un reconocimiento de derechos, sino la imposición de la voluntad del adulto. Un ejemplo de esta tendencia queda expresada en la reforma que se comenzó a aplicar al sistema judicial, a partir del modelo norteamericano, que significó la exclusión de los niños de la jurisdicción penal y la creación de un sistema de protección hacia la infancia desvalida. Este sistema tuvo características ambiguas, ya que mostraba rasgos que fueron considerados progresistas para la época y más benévolos hacia el niño (eliminación del castigo, aplicación de métodos educativos con base científica), pero a la vez se aplicaba de modo discrecional y amplio, lo que negaba derechos básicos ${ }^{13}$. Bajo la consigna de defender "el bien del niño" se podían imponer, por la vía de un paternalismo autoritario, fórmulas francamente abusivas ${ }^{14}$.

En las primeras décadas del siglo XX la doctrina jurídica basada en los derechos individuales comenzó a ser desplazada por los enfoques que proclamaron derechos económicos y sociales. Un precedente importante quedó reflejado en las constituciones de México (1917) y Alemania (Weimar, 1919), y principalmente en los convenios laborales promovidos a partir de la constitución de la OIT (1919), los que comprometieron a los Estados firmantes. Entre esas primeras normativas internacionales se encontraban algunas que protegían a los niños trabajadores. En este sentido, el movimiento en pro de los derechos del niño se vinculaba con un ambiente (notablemente convulsionado) que era cada vez más proclive a reconocer en el Estado una función central en la protección de derechos sociales y económicos.

Pero los primeros documentos que declararon los derechos del niño, y que veremos a continuación, no fueron solo una prolongación de este movimiento. En cierto sentido fueron más lejos que la mera aplicación de mecanismos asistenciales

12 El texto es citado in extenso en Veerman, The Rights of the Child, 435-437.

13 Sobre este tema en particular el balance ha sido notoriamente crítico, aunque en su época el nuevo sistema de protección fue presentado como una expresión del progreso de las naciones. Al respecto, véase Anthony Platt, The Child Savers. The Invention of Delinquency, Chicago, The University of Chicago Press, 1977.

14 Un ejemplo extremo de ello lo muestra el libro de la sicóloga Alice Miller, For your own good: Hidden Cruelty in Child-Rearing and the Roots of Violence, Farrar, Straus, Giroux, 1983, centrado en los métodos de crianza y educación en Alemania, desde el s. XIX. En la actualidad, el principio del "bien superior del niño", proclamado por la Convención de Derechos del Niño en 1989, debido a su indefinición y ambiguedad, parece tener ciertos rasgos paternalistas. 
que garantizaran ciertos beneficios materiales a los más débiles. Si bien este aspecto se consideró, también proponían defender las necesidades espirituales de los niños (algo que solía obviarse en el caso de los derechos sociales y económicos de los adultos), además de enfatizar el logro de la felicidad del niño como un todo indisoluble.

\section{LOS DERECHOS DEL NIÑO EN CHILE}

En Chile se conocieron varios autores y textos que defendían los derechos del niño, algunos de carácter institucional, otros personales, los que tuvieron distinto nivel de divulgación e influencia. El libro de Ellen Key circuló entre los intelectuales de inicios del siglo, aunque no alcanzó la difusión de John Dewey, Adolphe Ferriere y otros exponentes de la nueva pedagogía. Dentro del campo libertario, sin duda Francisco Ferrer fue la figura predominante, aunque obviado por los círculos oficiales. Bajo su influencia, la Federación Obrera de Chile y el Partido Comunista crearon escuelas racionalistas que alcanzaron cierto desarrollo entre 1921 y $1926^{15}$.

Entre los textos de origen institucional que proclamaron expresamente los derechos del niño hubo cuatro que se conocieron en Chile entre 1910 y 1930: el acuerdo de un congreso científico español, que data de 1912; la célebre declaración de Ginebra, suscrita por la Sociedad de Naciones en 1924; el texto firmado en Montevideo por los delegados de diez países, incluido Chile, en 1927, y la Declaración de Washington, de $1930^{16}$.

La primera declaración que hemos mencionado apareció entre las conclusiones del Primer Congreso Español de Higiene Escolar, realizado en Barcelona en 1912 (8-12 de abril). Aunque el citado encuentro se dedicó a varias materias relacionadas con la promoción de la higiene en las escuelas, el tema que alcanzó mayor difusión fue el de los "Derechos del Niño", iniciativa que probablemente fue promovida por el eminente pediatra Manuel Tolosa Latour ${ }^{17}$. En noviembre de 1912

15 Emilio Uzcátegui García se quejaba de la escasa difusión que tenían las ideas de Key, Tolstoi y Ferrer en la formación de los profesores. Para revertir esta situación, escribió Los pedagogos de la libertad, Iquique, s/e, 1923/1924. El caso de las escuelas nacionalistas lo veremos más adelante

16 Probablemente existan otras declaraciones que circularon pero no encontramos vestigios de ellas. Por ejemplo, el texto del pedagogo uruguayo José H. Figueira, de 1910, y reeditado en 1927 y 1939, al parecer tuvo solo alcance local. No obstante, lo citaremos más adelante ya que pareció influir en la declaración redactada por Rodríguez Fabregat. Otro uruguayo ilustre, Clemente Estable, presentó un texto en forma de decálogo en 1928. Ambos son mencionados en un documento del INN, $L a$ inclusión de la niñez con discapacidad, Montevideo, documento de trabajo del PRODER, IIN, julio/ 2001. La chilena Amanda Grossi menciona una iniciativa que circuló en el Primer Congreso Internacional de Economía Social, realizado en Buenos Aires, en 1924 (26 oct.- 4 nov.). El texto habría sido ratificado en Lima, en el Tercer Congreso Científico Panamericano, realizado entre diciembre de 1924 y enero de 1925. Amanda Grossi Aninat, Eugenesia y su legislación, Santiago, memoria para optar al grado de Licenciado en la Facultad de Ciencias Políticas y Sociales de la Universidad de Chile, Editorial Nascimento, 1941, 180. No tenemos más referencias de él.

17 En España, el texto apareció publicado en Pro-Infantia (Boletín del Consejo Superior de Protección a la Infancia y Represión de la Mendicidad), No 40, agosto/1912, 501-502. Sobre el papel de Tolosa, véase María Luisa Ramas Varo, La protección legal de la infancia en España: orígenes y aplicación en Madrid (1900-1914) Madrid, Consejo Económico y Social, 2001, cit. por María Belén 
un diario socialista de Iquique, El Despertar de los Trabajadores, hizo un comentario irónico sobre la declaración ${ }^{18}$. Al año siguiente el texto fue reproducido en la Revista de Higiene Práctica ${ }^{19}$. En 1914 volvió a publicarse, esta vez en La revista $a z u l$, un "quincenario ilustrado del hogar y de la economía doméstica", dirigido a la mujer de clase alta, aunque sin indicarse el origen del texto ${ }^{20}$. Al parecer, esta declaración tuvo amplia difusión en América Latina y no solo en Chile ${ }^{21}$.

El texto proclamado en Barcelona, en 1912, estaba compuesta de ocho artículos, antecedidos y precedidos de algunos párrafos aclaratorios que permitían darle mayor sustento a su contenido. Los primeros dan cuenta del ambiente higienista del congreso (cinco de los ocho artículos se relacionaban con protección física de los niños: derecho a la luz del sol; aire abundante; agua y limpieza; alimentación; ejercicio). Pero los últimos tres artículos demuestran cuánto había calado, en el ambiente científico, el ideal romántico de la infancia, que asociaba la niñez con la felicidad (derecho a la alegría, al amor, a la verdad). Sobre este último aspecto, el texto consideraba un crimen de lesa niñez flagelar a un niño o criarlo rodeado de tristeza. Incluso llegaba a plantear que se castigara con prisión de uno a tres años a quien golpeara, fuera con coscachos, reglas u otros instrumentos ${ }^{22}$.

Según la declaración, varios de estos derechos debían ser garantizados por la familia, y en subsidio por el Estado. Es decir, se avanzó en proponer instituciones responsables de cumplir estos propósitos.

Pocos años después, en Europa se gestó un segundo texto que alcanzó gran divulgación a nivel mundial, a pesar del carácter más restrictivo de su contenido, si lo comparamos con el documento aprobado en Barcelona. La iniciativa fue promovida inicialmente en Inglaterra por Eglantyne Jebb (1876-1928), quien redactó el texto. En 1919, junto a su hermana Dorothy, había fundado Save the Children Fund en Londres. Bajo su influencia, ese mismo año se creó en Suecia una institución homóloga, Radda Barnen. Poco después, en enero de 1920, con ayuda de la Cruz Roja surgió en Ginebra una nueva organización, Save the Children International Union ${ }^{23}$. Esta última institución hizo suya la declaración en febrero de 1923 y la proclamó oficialmente el 17 de mayo de ese mismo año. Ya en esta época el texto pasó a ser conocido como la "Declaración de Ginebra". En varias ceremonias solemnes el texto fue suscrito por destacadas personalidades (entre ellas, Ellen

Rodrigo Lara, La libertad de pensamiento y creencias de los menores de edad, Madrid, Memoria presentada para optar al grado de doctor, Universidad Complutense de Madrid, Facultad de Derecho, Departamento de Derecho Eclesiástico del Estado, 2004, 65-66.

18 "A los niños pobres" (Juan Cordero), en El Despertar de los Trabajadores, Iquique, 24/nov./ 1912,1 .

19 Revista de Higiene Práctica, s/n, 1913, 134-135.

20 La revista azul, $\mathrm{N}^{\circ} 1$, noviembre/1914, 20.

21 En 1916, en una revista publicada en Medellín se aludió a los Derechos del Niño que se proclamaron en este Congreso. Carlos Edward García Londoño, Niños trabajadores y vida cotidiana en Medellín, 1900-1930 (Medellín, Clío, Editorial Universidad de Antioquia, 1999), 63-64.

22 La revista azul, $\mathrm{N}^{\circ} 1$, noviembre/1914, 20.

23 También conocida como UISE, Union Internationale de Secours aux Enfants, o bien International Save de Children Union. En 1946 esta institución pasó a denominarse International Union for Child Welfare, IUCW. 
Key) y monarcas europeos. En uno de estos actos, el 21 de noviembre de 1923, desde la Torre Eiffel, la declaración fue leída en una transmisión radial por Gustave Ador, presidente de la Confederación Suiza y del Comité Internacional de la Cruz Roja ${ }^{24}$.

Compuesta de cinco principios, la declaración indicaba las condiciones esenciales que aseguraban el pleno desarrollo de su persona. Enfatizaba la protección material al niño, de un modo bastante pragmático y preciso (desarrollo físico y espiritual; alimentación; asistencia al enfermo, al niño desvalido y desviado; protección contra la explotación) por sobre los aspectos contemplados en la declaración española, mucho más amplia aunque de tono más lírico ${ }^{25}$. El derecho al juego, la felicidad, el amor, la autonomía y "a andar sucio", que ya habían sido considerados en otras iniciativas, aquí no estuvieron presentes. Tampoco se mencionaba la responsabilidad "subsidiaria" del Estado en la defensa de estos derechos. Por supuesto, el texto de Jebb se encontraba a mucha distancia del texto de Wiggin, de 1892, o del documento presentado en Moscú en 1918.

Por influencia de Save the Children International Union, finalmente la quinta asamblea de la Sociedad de las Naciones acordó en Ginebra, en septiembre de 1924, adoptar la Declaración de los Derechos del Niño, sin modificar el texto. Los delegados chilenos eran Armando Acharán, Enrique Villegas y Jorge Valdés.

En Chile, estos acuerdos alcanzaron una discreta difusión. Inicialmente la noticia pasó un tanto inadvertida, frente a otros hechos internacionales que acapararon los titulares de la prensa. Pero, poco después, las organizaciones asociadas a la Declaración que tenían presencia en Chile dieron muestras de cierta atención sobre el tema. En mayo de 1924, el gobierno chileno aprobó el reglamento de la Cruz Roja Juvenil y, con ello, según lo afirmó la propia Cruz Roja, habría adherido a la Declaración de Ginebra ${ }^{26}$. En abril de ese mismo año, Suzanne Ferriere, delegada de Save the Children International Union, con sede en Ginebra, visitó Chile para establecer contactos institucionales y solicitar cooperación para la Cruz Roja de Chile, sociedad correspondiente a la que ella representaba ${ }^{27}$.

La Union International de Secours aux Enfants envió un pergamino al IV Congreso Panamericano del Niño, realizado en Santiago en 1924, con la Declaración de los Derechos del Niño para que fuera firmado por los delegados. En la sesión de clausura la moción se aprobó por unanimidad y los delegados asistentes firmaron

24 Veerman, The Rights of the Child, 87-91 y 155-159.

25 Antecedentes, actas y trabajos del Cuarto Congreso Panamericano del niño, celebrado en Santiago de Chile en el Palacio del Congreso Nacional, los días 12 a 19 de octubre de 1924 (en adelante Cuarto Congreso Panamericano) (Santiago, Imprenta Cervantes, 1925), t. I, 148-149.

26 Aunque así se planteó, no tenemos claro cómo pudieron relacionarse ambos hechos. Decreto 1379, 7/mayo/1924, Ministerio de Instrucción Pública. Citado en Yo sirvo, No 4, junio/1930, 84 (el texto señala, por error, el mes de marzo, en vez de mayo). Esta adhesión también es mencionada en una lista de efemérides publicada en Yo sirvo, $\mathrm{N}^{\circ}$ 1-2, marzo-abril/1931 (contraportada).

27 La prensa tradujo la institución con el nombre de Unión Internacional de Socorro al Niño. Entre las entrevistas que desarrolló Ferriere estuvo una con el Patronato Nacional de la Infancia. El Diario Ilustrado, Santiago, 21/julio/1924, 10. 
su adhesión a la Declaración de Ginebra. En la misma ocasión adhirieron a la Oficina Internacional de Protección a la Infancia, con sede en Bruselas ${ }^{28}$.

Poco antes, en agosto de 1924, el escritor Ángel Custodio Espejo aludió en la prensa a los Derechos del Niño que se proclamaron en la Declaración de Ginebra. En un artículo hizo ver la necesidad de acompañar esta declaración con acuerdos prácticos que se encaminaran efectivamente a asegurar la protección del niño, lo que esperaba se produciría en el Congreso Panamericano del Niño ${ }^{29}$. En un libro de lectura publicado en 1925, y orientado a escuelas nocturnas de obreros, se incluyó el texto de la declaración ${ }^{30}$. En 1927 apareció un artículo firmado por Vicente Alfredo Riquelme en la Revista de Educación Primaria, donde este comentaba los derechos del niño. Su importancia radica en que era una publicación de amplia circulación entre el profesorado. En opinión del autor, el movimiento a favor de la infancia se había acentuado en Europa como consecuencia de la guerra y había llevado al surgimiento de un verdadero "culto al niño", en torno al cual se habían aunado muchas voluntades. En síntesis, los niños tenían derecho a nacer bien (es decir, se debía asegurar el bienestar de la madre), vivir bien (a partir de una crianza basada en criterios científicos) y educarse bien (una preparación integral para la vida). Esto significaba introducir una serie de cambios a nivel institucional y en la mentalidad de las personas ${ }^{31}$.

Entre 1928 y 1931, la revista de la Cruz Roja Juvenil, Yo sirvo, publicó en tres ocasiones la Declaración de Ginebra, que había sido adoptada por la Cruz Roja Internacional en 1923. Este parece haber sido el medio más masivo de difusión que tuvo la citada declaración, ya que la revista se distribuía en gran número en las escuelas $^{32}$.

En forma paralela surgió una iniciativa a nivel panamericano, originada a partir de la nueva institucionalidad a favor de la infancia que se estaba gestando. Recordemos que en el segundo Congreso Americano del Niño, en 1919 (realizado en Montevideo), se acordó dar cuerpo a una entidad permanente, para promover políticas hacia la infancia a nivel continental, bajo el nombre de Oficina Internacional Americana de Protección a la Infancia, con sede en la capital uruguaya. El promotor de la idea fue el pediatra uruguayo Luis Morquio, quien se comprometió a obtener el apoyo de su gobierno para llevar a la práctica la iniciativa. No se lograron avances antes de la organización del siguiente congreso, en Río de Janeiro (1922), por lo que en esa ocasión, por indicación de Cora Mayers, la delegada

28 El Mercurio, Santiago, 19/octubre/1924, 13. Cuarto Congreso Panamericano, t.I, 95-96, 101 y 148-149.

29 "La protección del niño" (Angel C. Espejo), en El Mercurio, Santiago, 10/agosto/1924, 5.

30 Carlos Prado Martínez y Jenaro Torres C., El lector del obrero chileno. Libro de lectura para las escuelas nocturnas del país y obreros en general. Adoptado como texto de lectura en las Escuelas Nocturnas Fiscales y Municipales de la República, Valparaíso, Fisher y Cía Impresores [1925], 187-188.

31 Revista de Educación Primaria, No 6-7, agosto-sept./1927, 239-243.

32 Yo Sirvo, $\mathrm{N}^{\circ} 1$, octubre/1928, contraportada; $\mathrm{N}^{\circ} 11$, octubre/1929, contraportada; $\mathrm{N}^{\circ} 4$, junio/ 1930, 84. En la Revista de Salud Pública, que la Cruz Roja chilena publicó entre 1922 y 1924, no se dieron noticias de la declaración. 
chilena, se insistió en la declaración de intenciones. Morquio obtuvo mayor apoyo a partir de entonces y logró que en julio de 1924 el gobierno uruguayo creara finalmente la Oficina, bajo su dirección honoraria, resolución que debía ser ratificada por los restantes países americanos. La propuesta, que incluyó un reglamento, fue presentada a consideración del IV Congreso, celebrado en Chile en octubre de ese año.

En ese encuentro se aprobó la formación de la nueva organización, bajo un nuevo nombre: Instituto Internacional Americano de Protección a la Infancia. Las conversaciones siguieron en los años siguientes, bajo la conducción de un consejo provisorio, y en junio de 1927 diez países suscribieron en Montevideo la constitución oficial del Instituto, dirigido por el doctor Luis Morquio ${ }^{33}$.

En la sesión inaugural que dio vida al Instituto, el 9 de junio de 1927, se aprobó el Decálogo de los Derechos del Niño, por iniciativa del Ministro de Instrucción Pública del Uruguay, Enrique Rodríguez Fabregat. En su encendido discurso, el ministro entregó "a la consideración de todos los hombres de buena voluntad y de sano corazón esta declaración de los Derechos del Niño, esta Tabla de Derechos en cuya observancia reposa el secreto de la grandeza y la gloria de las naciones y los pueblos" 34 .

El texto integraba un enfoque tradicional con uno más innovador. Por ejemplo, consideraba su protección física (vivienda, vestuario, seguridad económica, alimentación adecuada, condiciones sanitarias), así como el derecho a la educación. No se trataba de cualquier educación, ya que la declaración defendía un modelo pedagógico activo, no libresco, en contacto con la naturaleza, especializado. También incluía el derecho a la "consideración social", expresado en la igualdad jurídica (eliminación de las diferencias entre legítimos e ilegítimos), así como el derecho a mantener y desarrollar la propia personalidad y canalizar sus energías (lo que implicaba una crítica al modelo tradicional de los asilos y reformatorios). En otros aspectos el texto es ambiguo, ya que plantea el derecho a la alegría, pero poniendo mayor atención al bienestar material ${ }^{35}$.

Aunque no conocemos con exactitud el origen de este texto, podemos suponer que Rodríguez Fabregat tuvo a la vista un decálogo de los derechos del niño que había publicado José H. Figueira en 1910. No solo se asemeja en su estructura, sino también en su contenido ${ }^{36}$.

A partir de la organización del Instituto Internacional Americano y la declaración firmada en Montevideo, la idea de reconocer derechos a los niños comenzó a tener mayor divulgación en América Latina. De hecho, en el Congreso Panamericano del Niño de 1930, realizado en Lima, se discutió la necesidad de incorporar

33 Esta institución se transformó, con posterioridad, en el Instituto Interamericano del Niño. Los antecedentes y la constitución del Instituto en Boletín del Instituto Internacional Americano de Protección a la Infancia (en adelante BIIAPI), $\mathrm{N}^{\circ}$ 1, julio/1927, 7-14 y 29-66.

34 El texto completo está transcrito en BIIAPI, $\mathrm{N}^{\circ} 1$, julio/1927, 39-41.

35 BIIAPI, $\mathrm{N}^{\circ} 1$, julio/1927, 39-41.

36 El texto está transcrito en el Anexo. La declaración original fue publicada en el folleto Viejas y nuevas ideas sobre educación (1910). 
en la legislación interna de cada país una referencia explícita a la protección que se debía a los niños. Tras un largo debate, el primer código del niño fue promulgado en Uruguay en 1934 ${ }^{37}$. Aunque el texto de 1927 no estableció una obligación jurídica a los estados firmantes, se trataba de acuerdos en los que participaban representaciones oficiales de los estados y, por tanto, comprometía la voluntad de los gobiernos. Sin embargo, en Chile, la difusión del acuerdo firmado en Montevideo tuvo alcance limitado. La creación del nuevo Instituto, así como la firma del Decálogo de los Derechos del Niño, no tuvo mayor espacio en la prensa de la época $^{38}$. Según una autora, en mayo de 1928 los médicos chilenos hicieron suyo el decálogo. De ser efectivo, seguramente fue Luis Calvo Mackenna quien influyó en este acuerdo ${ }^{39}$.

En la primera Convención Internacional de Maestros, realizada en Buenos Aires en enero de 1928, circuló nuevamente el tema de los derechos del niño. De hecho, la declaración aprobada en Montevideo en 1927 fue presentada en el encuentro de profesores por el ministro de Instrucción Pública del Uruguay, Enrique Rodríguez Fabregat ${ }^{40}$. Nuevamente los acuerdos de la convención de maestros tuvieron una escasa divulgación en la prensa chilena, debido al ambiente de hostilidad hacia la delegación oficial, lo que opacó el contenido de las resoluciones. No era para menos, ya que la convención se había programado realizar en Santiago, pero las persecuciones políticas iniciadas en febrero de 1927 obligaron su traslado a Buenos Aires (no obstante el fugaz acercamiento entre la Asociación General de Profesores y el gobierno de Ibáñez). La prensa, controlada por la censura gubernamental, no le dio realce al encuentro ${ }^{41}$.

Gabriela Mistral, quien asistió a esta convención, presentó una ponencia titulada "Los Derechos del niño", que tuvo mayor divulgación fuera del país que en Chile $^{42}$. En el documento, consideraba principalmente aspectos espirituales (derecho a la salud plena, "al vigor y a la alegría"; a vivir en una sociedad con instituciones libres e igualitarias, que no hicieran diferencias entre los hijos). Otorgaba un lugar de privilegio a la educación profesional, maternal y cristiana ${ }^{43}$.

Detrás de este texto se encontraba una peculiar concepción de los derechos del niño, basada en el carácter excepcional de la infancia. Gabriela Mistral lo planteó claramente:

37 Los temas abordados en el VI congreso fueron transcritos en la Revista Chilena de Pediatría, $\mathrm{N}^{\circ}$ 5, mayo/1930, 272-279. El primer proyecto de Código del Niño uruguayo fue presentado en 1925. La referencia se la debo a la historiadora María Eugenia Jung.

38 Una escueta referencia en la sección cables en La Nación, Santiago, 10/junio/1927, 13.

39 Grossi, Eugenesia, 181. En la Revista Médica de Chile no se hace mención del acuerdo.

40 La noticia fue publicada en la revista El amigo, Santiago, N ${ }^{\circ} 72$, febrero/1929, 23.

41 La delegación chilena estaba dirigida por César Godoy Urrutia. El encuentro internacional estuvo tensionado por el retiro de algunas delegaciones y acusaciones diversas. Breves noticias de la Convención en La Nación, Santiago, 10 y 12/enero/1928.

42 Por ejemplo, el texto se publicó en el Boletín de la I.M.A. (Nº1, 1928) editado en Buenos Aires por la Internacional del Magisterio Americano; también en Amauta ( $N^{\circ} 12$, febrero/1928, 32), la revista peruana dirigida por Mariátegui (junto al texto de Rodríguez Fabregat, 33) y en el semanario Repertorio Americano, de Costa Rica (No 7, 18/agosto/1928, 106-107).

43 Gabriela Mistral, Magisterio y niño, selección de prosas y prólogo de Roque Esteban Scarpa, Santiago, Editorial Andrés Bello, 1979, 62-65. 
La infancia servida abundante y hasta excesivamente por el Estado, debería ser la única forma de lujo -vale decir, de derroche- que una colectividad honesta se diera, para su propia honra y su propio goce. La infancia se merece cualquier privilegio. Yo diría que es la única entidad que puede recibir sin rezongo de los mezquinos eso, tan odioso, pero tan socorrido de esta sociedad nuestra, que se llama "el privilegio", y vivir mientras sea infancia, se entiende, en un estado natural de acaparamiento de las cosas excelentes y puras del mundo, en el disfrute completo de ellas. Ella es una especie de préstamo de Dios hecho a la fealdad y a la bajeza de nuestra vida, para excitarnos, con cada generación, a edificar una sociedad más equitativa y más ahincada en lo espiritual $^{44}$.

Esto no significa que no se reconociera una vinculación estrecha entre el estatus de la infancia y la situación de la sociedad en su conjunto. La propia Mistral hacía notar que no existía nada que movilizara a los adultos con mayor ímpetu que la infancia. Esto debía tomarse en cuenta, considerando que el problema de la infancia no se remediaría sin resolver a su vez el problema social en su conjunto. En medio de un conflicto social de grandes dimensiones, la cuestión de la infancia tenía la virtud de unir a los adversarios más opuestos: "hasta los peores levantan la cabeza, oyen, se vuelven un momento nobles y acogedores, cuando se nombra al niño" 45 .

Al final de nuestro período de estudio, se hicieron públicas las conclusiones de la Conferencia de la Casa Blanca sobre Salud y Protección del Niño, realizada en Washington en noviembre de 1930. El texto incluía una declaración de derechos del niño (conocida como Children's Charter), que fue publicada al año siguiente en el boletín del Instituto Internacional Americano de Protección a la Infancia. Al momento de realizarse, la prensa chilena no prestó atención a la conferencia. A parecer, el texto no tuvo gran difusión en Chile ${ }^{46}$.

Las ideas que circularon en torno a los derechos del niño entre 1910 y 1930 no siguieron una orientación definida, ni llegaron a constituir una doctrina coherente. Como se puede observar en los textos expuestos, todos consideraron la necesidad de cubrir las necesidades básicas, de tipo material. También todos contemplaron el acceso a la educación. Unos pocos avanzaron hacia planos más subjetivos, incluyendo el derecho a la felicidad. El derecho la igualdad y la no discriminación fue incluido solo en unos pocos textos. Y el reconocimiento de la autonomía de los niños estuvo más bien ausente, salvo en aquellos que, bajo una inspiración libertaria, cuestionaban el poder que ejercían profesores y padres.

44 Mistral, Magisterio y niño, 62.

45 Idem, 63.

46 Entre otros aspectos, lo novedoso de esta declaración fue la inclusión del derecho a "ser comprendidos"; a ser protegidos contra el trabajo que impidiera su desarrollo físico y mental, limitara su educación y lo privara del derecho al compañerismo, la alegría y el juego; a proporcionar alivio y educación a los niños ciegos, sordos o lisiados y entregar protección y cuidado a los niños subnormales intelectualmente. La conferencia, White House Conference on Child Health and Protection, fue realizada entre el 19 y el 22 de noviembre de 1930. BIIAPI, $\mathrm{N}^{\circ} 4$ (t. IV), abril/1931, 730-775. 


\section{LA RECEPCIÓN}

La recepción en Chile de las ideas que en Europa y Estados Unidos circulaban sobre la infancia fue parcial y a veces su desarrollo se puede rastrear de un modo indirecto. En determinados temas, como veremos más adelante, las resistencias fueron mayores y los cambios demoraron en introducirse. Sin embargo, en ciertas áreas hubo innovaciones profundas, por ejemplo, en el plano legal, aunque estas transformaciones no se basaron solamente en una nueva concepción de la infancia, sino también en un cambio en la forma en que estaba siendo concebido el Estado.

En varios países la crianza de los niños había pasado a integrar un área de acción pública, cuando la función paterna era descuidada o claramente contravenía lo que la sociedad esperaba de ella. De esta manera, la paternidad comenzó a ser despojada de su inviolable carácter privado y el cuidado de los hijos pasó a ser un asunto con implicancias sociales.

El Código Civil había establecido en 1855 un marco de derechos y obligaciones entre padres e hijos, que dejó a los primeros con amplias atribuciones que vinieron a ser alteradas con la promulgación de la Ley de Protección a la Infancia Desvalida en 1912. Fue recién entonces que el Estado entró a disputar la tuición de los niños cuyos padres no cumplieran con su función esencial, en situaciones de evidente abandono y abuso. Por esa época el jurista francés Clément Griffe planteaba que el derecho del hijo debía primar sobre el derecho del padre ${ }^{47}$. Pero la ley de 1912 fue un paso en falso, ya que las limitaciones de la normativa la hicieron prácticamente inoperante ${ }^{48}$. El cambio efectivo se produjo a partir de la promulgación de la Ley de Menores, en 1928.

Hasta el sacerdote Emilio Vaisse, un defensor del modelo tradicional de paternidad, se mostró partidario de la "revolución" que introdujo el nuevo marco legal de 1928. El niño ya no sería más una persona sometida al poder discrecional del padre. Comentando el texto Los derechos del niño y la tiranía del ambiente, una obra de divulgación de la ley 4.447 escrita por el juez Samuel Gajardo, se mostró partidario de la idea expuesta por el autor: la intimidad del hogar no podía dejar indiferente al Estado. Un padre que corrompe a sus hijos no realiza un acto privado, sino uno de trascendencia social. Aunque favorable a la defensa del niño frente a todo aquello que lo corrompiera, sospechaba de los enormes alcances de esta

47 Citado por Armando Ricci Ferrari, La delincuencia infantil y los tribunales para menores. Estudio comparado de la ley $N^{\circ} 4447$, Santiago, Memoria de prueba para optar al grado de Licenciado en la Facultad de Leyes y Ciencias Políticas de la Universidad de Chile, Imprenta del Ministerio de Guerra, 1930, 196.

48 Por ejemplo, la ley se refería solo a los hijos legítimos, se limitaba a restringir el poder de los padres (no de las madres) y únicamente en el plano económico (afectando la figura legal de la patria potestad, bajo la fórmula establecida por el Código Civil chileno, y no la tuición y cuidado de los hijos). Además, no estableció un sistema asistencial que permitiera al Estado hacerse cargo de estos niños. Otras críticas surgieron debido a que las condiciones que establecía para suponer el abandono eran muy restrictivas y difíciles de cumplir. Un resumen de las críticas a la ley de 1912 en Hipólito Letelier González, La protección de la infancia, Santiago, memoria de prueba para optar al grado de Licenciado en Leyes y Ciencias Políticas, Imprenta S.B., 1918, 94-101. 
defensa de la moralidad en manos del Estado. Con todo, se inclinaba por aplaudir los beneficios del nuevo enfoque ${ }^{49}$.

Samuel Gajardo se transformó en un activo promotor de los "derechos del niño", desde sus primeros años como juez de menores. En el libro comentado por Emilio Vaisse, por ejemplo, citó la Declaración de Derechos del Niño, en una de sus versiones preliminare $\mathrm{s}^{50}$. En su opinión, la nueva legislación partía de un criterio moderno de la niñez, que no consideraba al niño como un hombre en miniatura, siguiendo la idea de Robert Gaupp ${ }^{51}$. La compleja mente del niño, sobre todo del que estaba expuesto a los peligros del ambiente, debía ser comprendida para actuar eficazmente en forma preventiva y para reformar su vida desviada.

Ya desde 1925 se venía planteando que el niño al ser sometido a un juicio no podía quedar expuesto por la prensa. La ley sobre abusos de publicidad penalizó la publicación de información relativa a delitos cometidos por menores, si no contaba con la autorización del juez (art. 26) ${ }^{52}$. La ley de menores de 1928 profundizó estos cambios, al establecer un sistema que excluyó del sistema penal a todos los menores de 16 años (y bajo ciertas condiciones a los menores de 20), eliminando el castigo y la defensa judicial, estableciendo un ágil procedimiento verbal y acrecentado el poder del juez ${ }^{53}$. Para el juez Gajardo y su tiempo, la legislación de menores era una muestra del nuevo estatus de la infancia, al fijar un criterio científico, pero a la vez benevolente, comprensivo y humanitario que no se limitaba a reprimir los actos (es decir, los delitos), sino que acogía a personas por su condición vulnerable en la sociedad. En la década de 1940, Gajardo se convertiría en un importante divulgador de la nueva doctrina ${ }^{54}$.

Otro promotor de los derechos del niño fue el médico Luis Calvo Mackenna. Además de su participación en varias instituciones a nivel nacional, sus contactos internacionales lo hicieron especialmente sensible al tema. Como ya lo adelantamos, había sido delegado oficial ante el Instituto Internacional Americano de Protección a la Infancia, que aprobó la Tabla o Decálogo de los Derechos del Niño, en 1927. En enero de ese año se había hecho cargo de la dirección de la Casa de Huérfanos, donde comenzó a incorporar varios cambios que disminuyeron notablemente la mortalidad infantil, redujeron el número de ingresos y facilitaron un sistema de adopción. Los resultados se debieron más a la labor personal de Calvo Mackenna que a una transformación institucional, que demoraría unos años más en

49 "Crónica literaria" (Omer Emeth, pseud. de Emilio Vaisse), en El Mercurio, Santiago, 26/ diciembre/1929, 3.

50 Resulta curioso que no haya citado la versión de 1924, aprobada por la Sociedad de Naciones. Samuel Gajardo, Los derechos del niño y la tiranía del ambiente (Divulgación de la ley 4.447) Psicología, educación, derecho penal, prólogo de Waldemar E. Coutts, Santiago, Imprenta Nascimento, $1929,41-50$.

51 Revista de educación, $\mathrm{N}^{\circ} 13$, enero/1930, 76.

52 DL 425, 20/marzo/1925, en Diario Oficial, 26/mayo/1925.

53 Sobre el nuevo sistema, véase Rojas, "Las acciones públicas hacia los niños, 1910-1930" (inédito)

54 Samuel Gajardo, Los derechos del niño, proclamados con motivo de la "Liga de los Derechos del Niño", el 25 de octubre de 1940 (Santiago, Impr. Universo, 1940); Los Derechos del niño, proclamados por la Unión Nacional de Protección a la Infancia en la semana del niño del Rotary Club el 19 de octubre de 1947 (Santiago, Impr. y Lit. Universo, 1947). El primer texto no está disponible. 
imponerse. En julio de 1929, también por su iniciativa, se cambió de nombre a la Casa de Huérfanos de Santiago por el de Casa del Niño, para evitar que se asociara al estigma del abandono. Esta idea, como hemos visto, estaba contenida entre los derechos proclamados por el Instituto ${ }^{55}$. Se dice que el doctor Calvo mandó colocar letreros en todo el establecimiento que decían: "Aquí se defienden los Derechos del Niño" 56 .

Los médicos pediatras presionaron activamente en torno a varios temas relacionados con la protección sanitaria de la infancia. La institucionalidad que surgió en los años 20 prefiguró el poderoso aparato de salud público que se extendió en la década siguiente. Uno de los mayores éxitos se obtuvo en el campo de la educación sanitaria, donde se ensayó, por primera vez, el control médico preventivo de los escolares a un nivel masivo. También se logró incentivar la lactancia materna. Pero este esfuerzo tenía ya varias décadas de camino recorrido y las bondades del amamantamiento estuvo presente en el congreso de protección a la infancia de $1912^{57}$. El cambio principal fue de énfasis: el uso de nodrizas pasó a ser calificado abiertamente como un crimen y la lactancia materna, un derecho del niño ${ }^{58}$. En la cartilla de puericultura que redactó la Sociedad Chile de Pediatría, y que comenzó a ser repartida junto con la libreta de matrimonio a partir de 1929, se especificaba el derecho a la alimentación materna: "toda madre puede y debe amamantar el mayor tiempo posible al niño". "El niño tiene derecho a la leche de su madre"59. En 1931 la lactancia materna quedó establecido incluso en el Código Sanitario, como un derecho del hijo ${ }^{60}$.

55 BIIAPI, N $\mathrm{N}^{\circ} 1$ (t. II), julio/1928, 70-86. [Casa Nacional del Niño], Memoria de la Casa Nacional del Niño. Breve reseña de su labor desde 1927 a 1934 inclusive, Santiago, Imprenta Casa Nacional del Niño [1934]. El cambio de nombre de la institución en Santiago se produjo a través del Decreto Supremo 1340, 16/julio/1929. Otro decreto, en 1930, amplió la medida a las restantes casas de huérfanos del país. Citados en Beneficencia, $\mathrm{N}^{\circ} 7$, agosto/1929, 385; $\mathrm{N}^{\circ} 8$ septiembre/1929, 475; $\mathrm{N}^{\circ} 14$ marzo/1930, 974.

56 La referencia a los letreros en la Casa Nacional del Niño aparece en Nelson A. Vargas Catalán, Historia de la pediatría chilena: crónica de una alegría, Santiago, Editorial Universitaria, 2002, 180-182; y en Ricardo Cruz-Coke, Historia de la medicina chilena, versión electrónica http:// docencia.med.uchile.cl/histmedicina/biograf.htm). Ambos no indican el origen de la información. El propio Calvo Mackenna no menciona esta situación al describir las innovaciones que introdujo en la institución.

57 Manuel Camilo Vial, Trabajos y actas del Primer Congreso Nacional de Protección a la Infancia, celebrado en Santiago de Chile del 21 al 26 de septiembre de 1912, Santiago, Imprenta, Litografía y Encuadernación Barcelona, 1912, 295-304.

58 Por ejemplo, Armando Zagal Anabalón, Lactancia y nodrizas asalariadas (ley Roussel) (Santiago, tesis de Licenciatura en Medicina, Clínica de Enfermedades de Niños. Prof extr. Luis Fuenzalida Bravo, Imprenta El Progreso, 1918), 3-8 y 13. También es el tono de la ponencia "Nodrizas mercenarias", presentada por J.M. Vergara Keller, en el Cuarto Congreso Panamericano, 86-91.

59 "Cartilla de Puericultura de la Sociedad Chilena de Pediatría", en Revista Chilena de Pediatría, $\mathrm{N}^{\mathrm{o}}$ 4, abril/1930, 213-216. "La Semana de la Madre", en Revista Chilena de Pediatría, $\mathrm{N}^{\circ} 1$, enero/1930, 51-53.

60 Según este Código la leche materna era de "propiedad exclusiva de su hijo" y por tanto la madre estaba obligada a amamantarlo hasta los 5 meses, salvo enfermedad. Tampoco podía amamantar a niños ajenos mientras el suyo no hubiera cumplido esa edad, a menos que un certificado médico de aptitud la habilitara. En ese caso, estaba obligada, así como los padres o tutores del segundo hijo, a declararlo ante la autoridad sanitaria (art. 44). Código sanitario, promulgado por DFL 226, 15/mayo/ 1931, Diario Oficial, 29/mayo/1931. 
En el terreno de la educación, aunque la escolaridad de los niños de extracción popular no quedó asegurada (al no crearse los mecanismos de auxilio escolar necesarios), se abandonó la concepción oligárquica que distinguía dos sistemas educacionales paralelos, uno orientado hacia los niños pobres y otro hacia los niños ricos. Ya nadie discutía (cuando menos públicamente) el carácter democrático de la educación. En los años 20 el sistema educacional era concebido, mayoritariamente, como un mecanismo abierto a la infancia en su conjunto y asociado a la función docente del Estado ${ }^{61}$. La idea de que todos los niños debían (obligatoriamente) acceder a la escuela se impuso, tanto por razones socioeconómicas como políticas y sicológicas. Detrás de esta política estaba presente la idea de que la educación era un requisito para el progreso y el desarrollo económico del país, la ampliación de la ciudadanía y la estabilidad institucional. Pero también era una necesidad de los propios niños, ya que iba a favor de su desarrollo integral como personas.

La reforma educacional, que comenzó a ganar terreno en el gobierno a partir de 1924 y se dio inicio con el decreto de diciembre de 1927, fue uno de los espacios más activos en la difusión de los derechos del niño. En 1928, en un documento dirigido a los padres, Luis Gómez Catalán defendía la nueva concepción de la infancia que se abría paso: el niño no era un hombre pequeño, sino una compleja realidad humana que debía ser estudiada y considerada en su plenitud. En su opinión, la escuela tradicional "contradecía la naturaleza humana". "Habían hecho una escuela para hombres chicos. Pero el niño es muy diferente del adulto. Así lo han demostrado las investigaciones científicas. El niño es sencillamente un niño, es decir, un ser con inteligencia distinta, cuerpo distinto, deseos y aspiraciones distintas a las del adulto. El que quiere hallar en el niño un hombre imperfecto, comete un disparate. En el niño no hay más que un niño. La escuela nueva cuida amorosamente que el individuo viva su infancia, reconociendo en el ser en crecimiento, una personalidad propia y evidente"62. Aceptar esta peculiaridad en la naturaleza del niño significaba que la escuela no solo debía prepararlo para su futura inserción social, sino promover que este experimentara, en cuanto niño, su participación en la sociedad. Así se entendió, por ejemplo, la temprana asimilación de los valores democráticos en los niños, incluyendo la noción de derechos y deberes.

Los nuevos enfoques pedagógicos criticaron las relaciones jerárquicas, que despreciaban las capacidades de las personas. La disciplina tradicional fue menos considerada y se comenzó a valorar la autodisciplina, lo que se tradujo a veces en la experiencia de la "república escolar". Esta tendencia se extendió también a nivel familiar. Varios testimonios revelan el peso que comenzaron a tener los niños al

61 El tema fue central durante el debate que, tras dos décadas, llevó a la promulgación de la ley de Instrucción Primaria Obligatoria, en 1920. El mecanismo institucional que consolidaba la segregación social era la existencia de los "cursos preparatorios" adosados a los liceos, lentamente eliminados a partir de 1920, aunque sin conseguirse hasta el final de la década.

62 "Si usted no ayuda al magisterio, la educación es incompleta", en La Nación, Santiago, 8/ abril/1928, 13 . 
interior del hogar, aunque probablemente esto se produjo en diferentes grados. El castigo comenzó a quedar deslegitimado, y la autoridad paterna disminuyó. Lo primero quedó incluso garantizado legalmente a fines de 1927 al prohibirse el uso del castigo físico en los estudiantes ${ }^{63}$.

Desde inicios del siglo XX se comenzó a estimular un gran número de organizaciones de niños, con fines diversos (sanitarios, recreativos, cívicos y pedagógi$\cos )$. El fundamento que se dio para ello fue tanto el interés de la patria, como el propio bien del niño. Los propósitos de estas organizaciones fueron más o menos acogidos y legitimados socialmente, en estrecha asociación con las organizaciones de adultos que estaban detrás de ellas. Así, las viejas y nuevas rivalidades entre masones, liberales, conservadores y comunistas se reprodujeron en este campo. El objetivo explícito de estas experiencias no era estimular la participación de los niños, sino asegurar una adecuada socialización en los niños en los valores cívicos que se sentían amenazados. La Asociación de Boy Scouts fue apoyada con entusiasmo por el Estado, así como la Cruz Roja Juvenil. En el polo opuesto, los "pioneros" y las escuelas racionalistas, organizadas por los comunistas, se consolidaron, aunque por un breve período. La Iglesia Católica organizó sus propios grupos de niños para resistir las amenazas a la fe. Varios de estos grupos fueron mirados con recelo por quienes se sentían en peligro por el tipo de socialización que estas organizaciones promovían. Las instituciones adultas que estuvieron detrás de las organizaciones infantiles tendían a descalificar el objetivo de las organizaciones rivales, enfatizando la finalidad "perversa" de los adultos ${ }^{64}$.

El debate sobre la educación religiosa en las escuelas se rigió también por este criterio. La libertad de conciencia quedó radicada en los padres, quienes finalmente debían decidir por el tipo de formación moral que estos recibirían.

La política de escolarización obligatoria y el fortalecimiento de la función docente del Estado fueron objeto de críticas, tanto por parte de los grupos católicos (favorecidos por la libertad de enseñanza) como de la izquierda comunista y anarquista (que intentaba constituir su propio sistema educacional). Ambos sospechaban de los objetivos ideológicos de la educación, pero finalmente debieron ceder ante el aplastante predominio de la nueva política.

En el debate sobre las consecuencias que estaba teniendo la "Cuestión social", la protección de los niños trabajadores fue uno de los puntos coincidentes de los diversos proyectos planteados, y uno de los aspectos contemplados en las primeras leyes laborales que se promulgaron. La alta participación laboral infantil desembocó, en algunos sectores, en la organización de huelgas de niños. Al parecer, estas se organizaron en forma espontánea, sin una activa participación de adultos. Pero el desconcierto surgió de cualquier modo, por las implicancias que podía tener esta temprana forma de socialización, que presagiaba un futuro de convulsiones laborales mayores.

63 Sobre este fenómeno, puede consultarse nuestros textos "Las imágenes de la infancia, 19101930" y "Los espacios de socialización de los niños, 1910-1930" (inéditos).

64 Sobre el particular, véase Rojas, Moral y prácticas cívicas. 
La nueva legislación laboral les reconoció a los niños el derecho a ser protegidos de ciertos abusos patronales, como imponer excesivas horas de trabajo o condiciones ambientales peligrosas. Pero era el Estado el encargado de aplicar la respectiva fiscalización, ya que a los propios niños no se les reconoció capacidad para hacerse representar directamente ${ }^{65}$.

En circunstancias muy contadas, los niños fueron convocados para defender ciertos derechos, como ocurrió con el acceso a la alimentación. En Antofagasta, a raíz de la aplicación de un impuesto a la leche condensada importada, se organizó un desfile de protesta en el que participaron madres e hijos. La revista Zig-Zag mostró la actividad y lo definió como un "mitin infantil" 66 . La campaña tuvo efecto, ya que el gobierno no tardó en fijar un precio máximo para este producto, en las provincias donde el consumo era masivo ${ }^{67}$.

Pero las acciones a favor de la protección material de la infancia (incluyendo el cuidado físico, la provisión de alimentación y vestuario) fueron las más frecuentes y las que movilizaron mayores recursos. Como en el siglo XIX, esta función siguió principalmente a cargo de las instituciones privadas dedicadas a la niñez desvalida, mantenidas parcialmente con recursos del Estado. En todo caso, nunca llegó a ser considerada propiamente una obligación jurídica que asegurara una cobertura plena, sino más bien una obligación moral que ponía en evidencia el nivel de civilización de un país.

La sensibilidad hacia los niños pobres debía contagiar incluso a los niños de la clase alta, quienes aprenderían así, a temprana edad, el sentimiento de la caridad. La filantropía infantil se desarrolló en las primeras décadas del siglo XX, quedando reflejada en instituciones como el Bando de Piedad. Pronto la caridad infantil se hizo extensiva a los sectores populares que estaban en condiciones de ayudar a quienes vivían una situación de mayor miseria. La Cruz Roja Juvenil, creada en 1923 y desarrollada principalmente en las escuelas primarias de niñas, se formó con esta misión.

El derecho a la alegría de los niños también se "democratizó" y comenzó a ser valorado por la prensa y las instituciones filantrópicas. Se canalizó principalmente por medio de la entrega de juguetes y la organización de paseos y matinés populares. Con ocasión de la Navidad se acentuaba esta sensibilidad. Así lo refleja este artículo, publicado en Zig-Zag en 1926:

he visto los niños que no tienen juguetes, los niños que no han espigado alegría, los que oyen con ojitos agrandados por un deseo impreciso, los acordes de la fanfarria, los ruidos de los pitos y el estampido de los cohetes que exteriorizan la alegría suburbial. He visto esos pobres niños, descalzos sobre un suelo que

65 En la práctica, grupos de niños ya venían realizando acciones reivindicativas desde antes de 1924, como lo hemos registrado en Los niños cristaleros: trabajo infantil en la industria. Chile, $1880-$ 1950, Santiago, vol. VI, Colección Sociedad y Cultura, Dibam, 1996, y Los suplementeros: los niños y la venta de diarios. Chile, 1880-1953, Santiago, Ariadna Ediciones, 2006.

66 Zig-Zag, $\mathrm{N}^{\circ} 1048,21 / \mathrm{marzo} / 1925$.

67 El Mercurio, Santiago, 19/marzo/1925, 11. 
abrasa, sucios, cubiertos de jirones de vestidos; los he visto en las calles jugando en los montones de tierra, mirando con una extraña nostalgia la vida. Ellos viven una cruel pesadilla, soportan el peso de una cadena que no merecen, ellos son tristes en la edad en que los demás niños, casi todos los niños, son alegres, son reyes de su casa ${ }^{68}$.

Pero esta valorización de la risa y el juego desbordó hacia otras esferas. Un autor incluso se propuso que el niño recluido en la cárcel no fuera alejado de su condición de niño, "ahogando sus francas carcajadas, entrabando sus juegos". Incluso en ese lugar "el niño debería reír y jugar", "el niño debe ser siempre niño"69.

En el campo jurídico, la igualdad entre niños legítimos e ilegítimos fue una idea que tuvo cierta divulgación, y fue incluida en los textos redactados por Gabriela Mistral y por Rodríguez Fabregat. Sin embargo, en términos legales no hubo mayores cambios, aunque circularon algunas propuestas para mejorar la condición de los hijos ilegítimos. En 1916, por ejemplo, el diputado Ramón Briones Luco presentó una moción para establecer un procedimiento de prueba judicial para la paternidad ilegítima. La propuesta era muy modesta en sus consecuencias, ya que solo intentaba establecer un mecanismo para efectos del pago de alimentos (sin consecuencias sobre la condición de hijo natural). Sin embargo, la idea no tuvo acogida y la situación se mantuvo invariable ${ }^{70}$.

El tema de la ilegitimidad fue discutido largamente en las tres primeras décadas del siglo XX. Entre 1901 y 1931 se escribieron cuando menos 22 textos jurídicos sobre el particular, la mayoría entre 1917 y $1931^{71}$. Varios de ellos eran meramente

68 "Los que olvidaron los Reyes Magos" (Florencio Hernández), en Zig-Zag, No 1090, 9/ enero/1926.

69 J. Félix Rocuart Hidalgo, La delincuencia infantil y los reformatorios de niños, Santiago, Imp. La Tarde, 1932, 22.

70 Raúl Varela Varela, Del reconocimiento voluntario de hijo natural y de la prueba judicial de su filiación (Santiago, memoria de prueba para optar al grado de Licenciado en la Facultad de Leyes y Ciencias Políticas de la Universidad de Chile, Imprenta de San José, 1924), 104-107.

71 Entre 1901 y 1916 registramos cuatro textos; y entre 1917 y 1931, dieciocho. Rafael V. Ramírez A., De los hijos ilegítimos (1901); José Clemente Fabres, Derecho de los hijos naturales. De la nulidad y rescisión. Nulidad de un testamento cerrado. Efectos de la nulidad absoluta (1908); Moisés Poblete Troncoso, Legislación sobre los hijos ilegítimos (cuestión social) (1912); Fabio Ciangherotti, De los hijos ilejítimos no reconocidos solemnemente (1915); Juan Jerónimo Ortúzar Rojas, Paternidad ilejítima i su investigación (1917); Raúl Ferrada Riquelme, De los hijos naturales y de los simplemente ilejítimos: sus derechos hereditarios (1918); Enrique Tapia Cruzat, Los hijos ilejítimos en nuestra legislación (1920); Elías Letelier Fredes, De la filiacion ilejítima (1922); Víctor Concha Garcés, Hijos ilegítimos (1922); Rolando Merino R., Comentario al título IX, libro I, del Código Civil. De los derechos y obligaciones entre padres e hijos legítimos (1923); Raúl Boza B., Filiación natural (1923); Enrique Urrutia Manzano, Estudio sobre el artículo 272 del Código Civil y de la irrevocabilidad del reconocimiento (1923); Juan de Dios Valenzuela del Río, Los hijos naturales en concurrencia del cónyuge y hermanos legítimos (1924); Fernando Errázuriz Lastarria, De la investigación de la paternidad ilegítima (1924); Raúl Varela Varela, Del reconocimiento voluntario de hijo natural y de la prueba judicial de su filiación (1924); Alfonso Arancibia A., El problema de la indagación de la paternidad ilegítima y su solución en el Código Civil (1926); Carlos Verdugo Verdugo, La Investigación de la Paternidad Ilegítima (1927); Antonio Mancilla Cheney, De la Investigación de la paternidad ilegítima, especialmente en Chile, Francia, Bélgica, Suiza y Alemania (1928); Gregorio Fuentes 
descriptivos y se detenían a detallar la consistencia jurídica de las normas, pero unos cuantos se planteaban críticos frente a la legislación vigente por entonces, por diversas razones, y sugirieron cambios ${ }^{72}$. Todos reconocían la necesidad de mantener la diferencia entre hijos legítimos e ilegítimos, pero proponían algunas reformas, a veces para hacer coherente la norma, o bien para ampliar el acceso a la condición de hijo natural o eliminar las categorías al interior de los hijos ilegítimos. Por ejemplo, Varela criticaba que a los hijos de padres adúlteros e incestuosos (es decir, que cabían en la condición de "dañado ayuntamiento") se les negara la condición de hijos naturales, cuando la tendencia del derecho moderno buscaba no acentuar la culpa de los adultos en los hijos. Criticaba, además, que se negara la prueba judicial para efectos de establecer la paternidad ilegítima (tanto para el pago de alimentos como para alcanzar la condición de hijo natural), una norma que se había copiado de la legislación napoleónica. Tras un siglo de discusiones sobre tal prohibición, en su opinión estaba más que probado que era una medida injusta e ineficaz ${ }^{73}$.

Efectivamente la legitimidad había crecido desde la dictación del Código Civil. En 1855 en promedio había 226 ilegítimos por cada mil nacidos, y en 1921 la cifra se elevaba a $373^{74}$. Aunque este aumento no podía adjudicarse totalmente a una profundización efectiva del fenómeno, fue colocado como argumento en contra de la efectividad de la legislación ${ }^{75}$. Sin que se produjeran cambios institucionales significativos, a fines de esa década la ilegitimidad comenzó a declinar.

Letelier, otro autor, también criticaba que la paternidad quedara sujeta a la voluntad del padre. El reconocimiento de la maternidad era bastante más expedito, lo que era una evidencia de discriminación. En su opinión, los argumentos que se habían esgrimido en su momento no eran válidos (dificultad de probar la paternidad, evitar acusaciones infundadas, contener la ilegitimidad, evitar un escándalo público). Según Letelier los efectos sociales de todo esto eran extremadamente dañinos (mortalidad infantil, abortos, infanticidio, abandono). El interés social estaba justamente en no dejar abandonados a estos niños. Para revertir esta situación proponía no solo regular la indagación de la paternidad, sino también establecer la

O., De los hijos naturales (1929); Pablo Favero Latorre, Sistema de legitimación y de reconocimiento como naturales de los hijos ilegítimos (1929); Emilio Grant Benavente, La madre y los hijos ilegítimos ante el derecho civil y social (1930); Manuel Somarriva Undurraga, La filiación: estudio doctrinal y de legislación comparada (1931)

72 Entre los que plantearon críticas: Raúl Boza B., Filiación natural, Santiago, memoria de prueba para optar al grado de Licenciado en la Facultad de Leyes i Ciencias Políticas de la Universidad de Chile, Imprenta Comercial, 1923; Varela, Del reconocimiento voluntario, citado; Elías Letelier Fredes, De la filiación ilejítima, Concepción, memoria de prueba para optar al grado de Licenciado en la Facultad de Leyes y Ciencias Políticas de la Universidad de Chile, Imprenta y Encuadernación Moderna, 1922.

73 Varela, Del reconocimiento voluntario, 56-58 y 94-134.

74 Idem, viii.

75 Es probable que el registro estadístico de hijos legítimos e ilegítimos se haya visto seriamente afectado a partir de la ley de matrimonio civil, en 1884. A partir de entonces, muchos matrimonios religiosos que no formalizaron su situación civil pasaron a engrosar la condición de hijos ilegítimos. Esto fue advertido por Letelier, De la filiación ilejítima, 3-4. 
precedencia del matrimonio civil al religioso ${ }^{76}$. Este y otros textos justificaron una reforma, pero se plantearon a favor de disminuir las diferencias legales, sin eliminarlas totalmente.

En el Congreso Panamericano del Niño de 1924 dos ponencias se inclinaron por una reforma legal que permitiera la investigación de paternidad. Finalmente se acordó proponer que se permitiera la indagación, aunque con condiciones. No estaría permitida cuando la madre tuviera mala conducta y solo se autorizaría el procedimiento en algunas situaciones ${ }^{77}$. No obstante la discusión, los cambios fueron menores. La única excepción se produjo en la ley de accidentes laborales de 1924, que otorgó beneficios comunes para los hijos, fueran estos legítimos o ilegítimos $^{78}$. El gobierno, por su parte, trató de incentivar el matrimonio legal a través de una política "persuasiva" de los funcionarios encargados del Registro Civil 79 . Recién en 1935 se incorporaron algunas de las reformas planteadas diez años antes $^{80}$.

No obstante el interés público por el tema del abandono de niños, no hubo mayor preocupación por reconocer legalmente la adopción. En el Congreso de Protección a la Infancia de 1912, una ponencia de Alejandro Lira se mostró favorable a legislar al respecto ${ }^{81}$. El tema se trató en los congresos panamericanos del niño en 1916, 1919, 1922 y 1924. En este último, un delegado chileno expuso sobre el tema y propuso un cambio legal ${ }^{82}$. Pero la idea no tuvo mayor eco, como tampoco un proyecto de ley presentado en junio de 1929 por el diputado Rafael Moreno. El vacío del Código Civil fue resuelto recién $1943^{83}$. Tampoco encontró

76 Letelier, De la filiación ilejítima, 3-4 y 45-51.

77 Se propuso permitir la investigación dentro del plazo de dos años (contados desde el nacimiento). El derecho quedaba limitado a los casos de seducción dolosa, rapto o violación y "concubinato notorio"; también a la existencia de documentos donde se reconociera la paternidad. Pero no se autorizaría la investigación si la conducta de la madre no permitiera fundar presunción de paternidad durante la convivencia. Cuarto Congreso Panamericano, t. I, 135-136; t.V, 50-68. Varela, Del reconocimiento voluntario, 99-100.

78 Ley 4055, 8/sept./1924, Diario Oficial 26/sept./1924, art.14.

79 Al momento de contraer matrimonio, el oficial del registro civil debía insinuar la necesidad de inscribir a los hijos ya nacidos, un trámite sin costo. Esta política ya se había planteado antes de 1930, a través del registro en zonas apartadas. "El gobierno se encuentra empeñado en obtener la legalización de la familia chilena", en La Nación, Santiago, 21/nov./1930, 1; "Por la mujer y por los hijos" (edit.), en La Nación, Santiago, 24/nov./1930, 3.

80 Los cambios fueron limitados: se eliminó la calidad de hijos ilegítimos de "dañado ayuntamiento" (dejando solo dos: simplemente ilegítimos y naturales) y se admitió la investigación de la maternidad y paternidad ilegítimas, solo para efectos del pago de alimentos. Ley 5750, sobre pago de pensiones y represión del abandono de familia, 30/nov./1935, Diario Oficial. 2/dic./1935, Min. Justicia. Recién en 1952, con la ley 10.271 (29/febrero/1952, Diario Oficial., 2/abril/1952) se modificó la condición de hijo natural y se estableció un procedimiento para el reconocimiento de los hijos naturales, entre otros cambios.

81 Vial, Trabajos y actas, 511-515.

82 Ponencia de Carlos Estévez Gazmuri, en Cuarto Congreso Panamericano, t.V, 9-16. Luis Soto Bórquez, La adopción en nuestra legislación civil (Santiago, memoria de prueba para optar al grado de Licenciado en la Facultad de Ciencias Jurídicas y Sociales de la Universidad de Chile, Imp. La Tarde, 1929), 74-75.

83 Soto, La adopción, 7-8, 74-75, 89, 96-101. Entre los pocos textos anteriores que se escribieron sobre el tema: Luis R. Valenzuela, La adopción ante la lei chilena. Estudio hecho a propósito del primer caso de adopción que se presenta ante nuestros tribunales (1885); J. M. Ide Martínez, La 
acogida la elevación de la edad mínima de consentimiento sexual, que permaneció en $\operatorname{los} 12$ años ${ }^{84}$.

Lentamente el tema de los derechos del niño se fue imponiendo fuera del círculo de los expertos. En las sucesivas ediciones del Manual para las madres, de Lorenza, se incorporó el tema de los derechos del niño. Aunque el texto se dedicaba a entregar consejos prácticos sobre el embarazo, los métodos de crianza, la alimentación y las enfermedades infantiles, el primer estudio se refería a "Los Derechos del Niño", sin seguir ninguno de los textos que ya circulaban. El primer derecho era a "nacer con un cuerpo sano y una mente despejada"; el segundo, "ser amado y respetado en su individualidad; [...] ser desarrollado en mente, cuerpo y alma; [...] ser protegido de las enfermedades, de las influencias malsanas y de personas malévolas, y [...] gozar de algunas oportunidades en la vida"; y el tercero, el derecho al "medio ambiente en que mejor pueda desarrollar sus poderes y su talento" 85 .

Si bien el concepto de derechos del niño tuvo cierta acogida en el ambiente intelectual y político de comienzos del siglo XX, la situación de los niños y el fuerte debate ideológico hizo que el tema se moviera dentro de un terreno mucho más contradictorio y movedizo.

\section{LAS RESISTENCIAS}

La difusión de los derechos del niño se encontró con distintas formas de resistencia. Algunas provenían del ambiente radicalizado de la época, que no podía concebir que coexistiera una extrema sensibilidad hacia los niños pobres y una gran indiferencia hacia las demandas que hacían sus padres trabajadores. Los sectores populares más vinculados a la izquierda revolucionaria no pensaban que la acción del Estado ni la filantropía, y menos las declaraciones de derechos del niño, podrían resolver la situación de marginalidad de los niños pobres. Por esa misma razón, las referencias a estas declaraciones fueron muy escasas.

Un texto que comentaba la primera declaración de derechos del niño que se conoció en Chile, en 1912, es bastante demostrativo de este enfoque. El artículo

adopción en el derecho romano $i$ en el Código Civil alemán. Necesidad de establecerla en Chile (1901). La primera ley de adopción fue promulgada recién en 1943 (Ley 7613, de 11/mayo/1943, Diario Oficial, 21/oct./1943).

84 En la Sociedad de las Naciones no se propuso una elevación de la edad, por la resistencia de varios países, pero hubo cierto clima favorable, como medio para prevenir el embarazo precoz y acentuar la penalización de la trata de blancas. Al respecto, puede consultarse el artículo de Eugenia Scarzanella, "Los pibes en el Palacio de Ginebra: las investigaciones de la Sociedad de las naciones sobre la infancia latinoamericana (1925-1939)", en Estudios Interdisciplinarios de América Latina y el Caribe, vol. 14, N ${ }^{\circ}$ 2, julio-dic./2003 (disponible en http://www.tau.ac.il/eial/XIV_2/scarzane.html ) En Chile el cambio legal se produjo recién en 2003, al elevarse entonces el límite del consentimiento sexual a 14 años de edad.

85 Este texto aparece en la edición de 1929, el único que hemos podido consultar. El Manual se publicaba desde 1922, no sabemos si con el mismo contenido. Lorenza, Manual para las madres (s/a, s/e.), 17. La edición citada lleva una introducción de Cora Mayers, y por los datos estadísticos que contiene debe ser de 1929 
estaba dirigido a "los niños pobres" y hacía notar la inconsistencia de la mencionada declaración que, por "deporte", hacían "sesudos pedagogos-humanitaristas". A los niños abandonados se les aseguraba que tendrían derecho al sol, al aire y al alimento, pero con la "particularidad de que si, acosados por el hambre os apoderáis de un pan para alimentaros ó un pedazo de tela para cubrir vuestras carnes, entonces esos sesudos señores que teóricamente reconocieron vuestros derechos, os tratarán de ineducados, de pillos y de otros epítetos que la hipocresía imperante aplica á los que nada tienen, y azuzarán a la policía para que os prenda como la cosa mas natural del mundo". La situación no era mejor con los niños pobres que tenían hogar y padres responsables. Si estos se daban cuenta que sus hijos tenían derecho a la vida y reclamaban aumento de salario "esos mismos señores, en nombre del orden y de la legalidad establecida, los tratarán de exigentes y perturbadores" y si cojían algo para mitigar el hambre de sus pequeños, los tratarían de ladrones. Los niños pobres vivían demacrados por las enfermedades, "afligidos y atormentados por los deseos de poseer un juguete o un trajecito", como los que tenían los hijos de padres ricos. El vestuario, el alimento y los juguetes le estaban prohibidos por las instituciones, respetadas y reverenciadas "por los mismos señores que en un momento proclamaron vuestros derechos para demostrar que caminan con la corriente del siglo" 86 .

Pero aunque la declaración formal de derechos no encontró acogida entre anarquistas y socialistas, estos grupos se mostraron abiertamente favorables a limitar al autoridad paterna, excluir el castigo, democratizar la escuela, mejorar las condiciones materiales y lograr la felicidad de los niños en un sentido bastante radical. De hecho, fue al interior de los grupos anarquistas y comunistas (sin predominar completamente) donde se forjó el enfoque más radical en torno a los derechos del niño, que contempló incluso la promoción de formas activas de participación social y el reconocimiento de la autonomía del niño. En este sentido, la izquierda fue tanto tributaria del ideal romántico de la infancia (lo que se tradujo en su demanda de mayor protección hacia el niño), como de un modelo amplio de democracia que contemplaba limitar todas las formas de desigualdad entre las personas (basadas no solo en diferencias de clase, sino también de género, etnia y edad). Obviamente esta lucha se resolvería finalmente con el triunfo de la revolución, pero no pocos proponían un avance sustantivo en esta materia a través de la educación. Fue la propuesta, por ejemplo, de Francisco Ferrer.

En el vértice opuesto, los grupos más tradicionalistas se mostraron críticos al nuevo estatus de la infancia, en particular, al trato excesivamente condescendiente que se estaba dando a los niños. En el ámbito escolar, fue esto lo que impidió que se pudieran extender algunas experiencias pedagógicas que relajaron la disciplina y auspiciaron el autogobierno, sobre todo con ocasión de la Reforma de $1928^{87}$.

86 "A los niños pobres" (Juan Cordero), en El Despertar de los Trabajadores, Iquique, 24/nov./ 1912,1 .

87 Un comentario crítico a algunas concepciones excesivamente liberales, en el texto de Adolfo Ferriere, La educación nueva en Chile (1928-1930), versión española de F. Gallach Palés, Madrid, Bruno del Amo, 1932. 
Varios textos relataban, en tono irónico o abiertamente crítico, la nueva condición que creaba el "rey de la casa" y la pérdida de autoridad de los padres ${ }^{88}$. Roxane, uno de los personajes más reconocidos en su preocupación por los niños, se lamentaba en 1925 de la predominante tendencia a dar en el gusto a los hijos sin ningún límite, lo que anulaba todo principio de autoridad. En su opinión, abundaba el tipo de niña y niño "regalón", egoísta y caprichoso ${ }^{89}$. Este tono permite suponer que las resistencias culturales fueron importantes, y que este cambio de conducta no llegó a generalizarse. En 1918, Ernesto Montenegro comparaba la forma en que se trataba a los niños en Estados Unidos y en Chile y hacía notar las diferencias: en nuestras ciudades, una madre con su hijo en brazos no recibía las atenciones que eran comunes en la sociedad norteamericana, como él mismo lo había podido comprobar $^{90}$.

Algunos sectores siguieron poniendo en duda el amor materno. Por ejemplo, se enrostraba que el uso de nodrizas siguiera estando extendido en la clase alta, como una muestra evidente del poco interés que tenían las madres sobre sus hijos ${ }^{91}$.

Respecto de los sectores populares, Luis Calvo Mackenna reaccionó frente a la "pasmosa, desconcertante y brutal indiferencia con que las madres del pueblo acuden para abandonar definitivamente a sus niños, muchas veces de varios meses de edad", a la Casa de Huérfanos. Esto se reflejaba en la "tranquilidad inconcebible" con la que insistían para que sus hijos les fueran aceptados; la "frialdad aplastante" con la cual los veían desaparecer para siempre de su vista y los entregaban "como una cosa que dan" por ser de su propiedad; "la terrible naturalidad con que reclaman el paletocito tejido y los botincitos de punto que al niño abrigaban, todo sin un gesto de remordimiento, de compasión ni de dolor"92.

Calvo Mackenna cuestionaba la idealización que, según él, se hacía de "la bondad de las madres de nuestro bajo pueblo", aunque reconocía que la inmensa mayoría de ellas poseía un "alto grado de afección" hacia sus hijos. Una excepción generalizada de este hecho "constituiría una aberración de la naturaleza". Sin embargo, su experiencia en policlínicas, hospitales, gotas de leche, asilos y orfelinatos, "en verdadero contacto con el pueblo, aquel pueblo inculto y miserable del arrabal y del suburbio", le hacían ver otra realidad:

sabemos que hay allí madres que castigan la pequeña desobediencia de un niño que empieza a andar, con horas de oscuro encierro, a ración de pan y a ración de agua; sabemos que el látigo, enrollándose en una tierna cabecita y haciendo sangrar el rostro con el duro nudo de su punta, pretende de correctivo de una

88 Un ejemplo de esto es el artículo "Las matinés infantiles" que apareció en 1902, donde se caricaturizaban los absurdos caprichos del niño (El Ferrocarril, Santiago, 22/oct./1902). En la revista Familia, por su parte, Emilio Vaisse escribió contra la pérdida de autoridad en el hogar. Familia, $\mathrm{N}^{\circ}$ 54 , junio/1914, 1.

89 Roxane, "Notas sociales", en Zig-Zag, No 1084, 28/nov./1925.

90 "Su graciosa majestad el niño" (Ernesto Montenegro), en Zig-Zag, № 716, 9/nov./1918.

91 Por ejemplo, "Nodrizas mercenarias" (J.M. Vergara Keller), en Cuarto Congreso Panamericano, $86-91$

92 BIIAPI, $\mathrm{N}^{\mathrm{o}} 1$, julio/1928, 74. 
falta insignificante; sabemos que la gruesa tranca de una puerta rompe muchas veces la cabeza tierna que forjó una locura inocente; sabemos, por fin, que si labiecitos airados prorrumpen en una queja violenta contra aquel trato inhumano, pueden hasta ser infernalmente sellados con la plancha candente o con la brasa que en el brasero aquella misma plancha caldeó. No digo que estos hechos sean frecuentes, pero sostengo que no son tan excepcionales como generalmente se piensa ${ }^{93}$.

Esas madres "desnaturalizadas", que eran capaces de estos "tremendos rigores" con sus hijos de algunos años de edad, no sentían la menor compasión hacia el recién nacido, "ese nuevo ser que ni siquiera sienten que a ellas pertenece y al cual no les une ni la sombra de un afecto" 94 . Como se ve, en el balance que hacía el médico, gran parte de la responsabilidad recaía en la madre, como si el padre no existiera. Según Calvo Mackenna, si bien el contexto social de pobreza explicaba el abandono de niños en las casas de huérfanos, el desinterés de las madres era también un factor de importancia. En todo caso, en sus textos se cuidaba de generalizar en estas materias.

En el ámbito público, las colectas públicas a favor de la infancia, así como las actividades sociales orientadas a conseguir fondos, movilizaron muchos recursos y llenaron páginas en revistas y diarios. Lo que inicialmente había sido un espacio para la sociabilidad de la clase alta, se transformó en una actividad masiva, de gran convocatoria. Sin embargo, fue este mismo proceso el que generó resistencias, debido, por ejemplo, al exceso de colectas públicas ${ }^{95}$.

En contraste con el clima que surgió en torno al Congreso Panamericano del Niño, en 1924, el Intendente de Santiago se lamentaba de la escasa respuesta que recibía cuando solicitaba la ayuda de las clases altas. En una entrevista aparecida en Zig-Zag, Alberto Mackenna enrostró esta inconsecuencia. Olga Cousiño había sido la única persona de buen corazón que había encontrado en Santiago. "Habrá otras; pero yo no las conozco". Durante dos años hizo todo lo posible para ofrecer protección a unos 50 chiquillos que la policía había recogido de la calle y nada dio resultado. Incluso una dama de la alta sociedad les arrendó un miserable local a un alto precio. "Una institución que proclama su piedad por bando [¿Bando de Piedad?], me recibió muy bien la idea de establecer un lazo entre los niños pobres y los niños ricos, procurando que cada uno de estos diera algo en favor de aquellos. Hablaron, se movieron, publicaron artículos, celebraron un congreso del niño, nombraron delegados, embajadores nacionales e internacionales. Todo salió de allí excepto lo que se pedía y necesitaba: dinero, ayuda. Sin la generosidad de Olga Cousiño, los chicos vagos habrían salido a la calle a morirse de hambre. Esto hay que decirlo" 96 .

\footnotetext{
93 Idem.

94 Idem.

95 Zig-Zag, Nº 955, 9/junio/1923.

96 "Cincuenta niños vagos", en Zig-Zag, No 1063, 4/julio/1925.
} 
Cuando en diciembre de 1928 el diario La Nación escribió sobre la mendicidad infantil, dejó en evidencia la multiplicidad de argumentaciones que circulaban. Primero se mostró preocupado por el peligro social que esta significaba (un foco de delincuencia y la pérdida de seres útiles a la sociedad). A continuación agregó su interés por los propios niños: "No es menos digno de consideración el propio destino futuro de esos infelices. Irresponsables de ser como son, tienen derecho a que la sociedad se preocupe de ellos, los salve y los sustraiga a la sombría suerte a que aparecen predestinados". Pero luego prestó atención a las consecuencias estéticas que provocaban: "Y son además un desagradable y desprestigiador lunar para la ciudad. Sucios, haraposos, pedigüeños, soeces en el hablar, sugieren ideas bien poco halagadoras acerca de la sociedad a cuyo margen viven pero a la cual pertenecen en realidad" 97 . El interés por los niños parecía desvanecerse con rapidez.

Revertir la alta mortalidad infantil fue un objetivo central en la política pública desde fines del siglo XIX, tendencia que se profundizó con el auge de la pediatría. Aquí también se apreciaban los múltiples intereses en juego: el prestigio internacional, el fortalecimiento de la capacidad económica de la nación y la valoración de la infancia. No obstante los altos niveles de mortalidad, la estrategia del Estado no contemplaba disminuir la tasa de fecundidad. Al contrario, el tamaño de las familias era apreciado como un factor de progreso. La política pronatalista siguió predominando. Incluso los partidarios chilenos de la eugenesia fueron cautos en proponer medidas de control y no mencionaron el aborto, la esterilización ni el uso de técnicas anticonceptivas ${ }^{98}$.

El control de la natalidad fue un tema que surgió en forma contemporánea a la valoración de la infancia, aunque su vinculación no es directa. Ciertas corrientes feministas lo transformaron en una bandera de lucha, al igual que algunos grupos anarquistas y socialistas. En el periódico obrero La Palanca, de tendencia feminista y socialista, se defendió el control de la natalidad en un artículo publicado en $1908^{99}$. El 3 de mayo de 1913, Clara de la Luz (seguramente un seudónimo) realizó una conferencia en el Centro Demócrata de Santiago donde se observó una clara influencia neomalthusiana, en particular de la revista y editorial española Salud y Fuerza ${ }^{100}$. En Chile circularon varios de sus folletos, entre ellos ;Huelga de vientres! Medios prácticos para evitar las familias numerosas (1905, con varias reediciones), del anarquista Luis Bulffi, y Jeneración consciente, de Frank Sutor. Esta obra ilustrada incluía "grabados y figuras anatómicas, aparatos y objetos de preservación sexual". La editorial española divulgaba el uso del "obturador uterino",

97 Cit por Ricci, La delincuencia infantil, 36-38.

98 La ley de Defensa de la Raza de 1925 restringía el matrimonio entre personas que pudieran transmitir taras o enfermedades hereditarias, pero no mencionaba el aborto ni la esterilización de los enfermos.

99 Artículo firmado por Yedra, en La Palanca, agosto/1908, 19, cit. por Asunción Lavrín, Mujeres, feminismo y cambio social en Argentina, Chile y Uruguay, Santiago, vol. XXXIX, Colección Sociedad y Cultura, Dibam, 2005, 171-172.

100 La mujer y la especie, Santiago, Imprenta Lee y CA, 1913. 
inventado por entonces ${ }^{101}$. Según su propuesta, la defensa del niño, de la mujer y de la humanidad quedaba garantizada en una nueva actitud frente a la reproducción. El control de la natalidad permitiría la liberación de la humanidad.

En 1913, otro artículo a favor de los anticonceptivos apareció publicado, esta vez en El Despertar de los Trabajadores de Iquique. Su autor era Víctor Soto Román un dirigente de ambigua militancia anarquista y demócrata ${ }^{102}$. Aunque no sabemos el nivel de acogida de estas campañas, la propaganda no cesó en los años siguientes. En 1926 y 1927 el periódico anarquista El Sembrador incluyó textos favorables al control de la natalidad ${ }^{103}$. Por entonces, ese mismo periódico denunciaba la resistencia que había provocado en la autoridad sanitaria la distribución del folleto, Jeneración consciente de Sutor, que -como se ve- todavía circulaba. Responsabilizado de conspirar contra la moral y las costumbres honestas, el polémico texto mostraba en detalle las técnicas anticonceptivas ${ }^{104}$.

El control de la natalidad no era aceptado por algunos sectores socialistas. Completamente en contra de estas prácticas se manifestó un editorial de La Federación Obrera, publicado en julio de 1923. Comentando una conferencia del doctor Alejandro del Río, criticaba los cambios que se habían producido en el país en el campo de la maternidad. "Medio siglo atrás las funciones generales de la maternidad eran satisfechas conforme a las prescripciones de la naturaleza y cuando un desliz podía provocar escándalos, la autora se ocultaba pero cumplía regularmente el mandato de la naturaleza, que daba un hijo más a la patria, aunque creciera perdido en el montón de los anónimos". Esa madre cumplía con su función de mujer y la maternidad la fortalecía para los embates de la vida. Pero hoy la alta sociedad imponía otras preocupaciones superfluas y la mujer no se dedicaba a satisfacer las necesidades fisiológicas de la humanidad. En la clase dirigente, el hecho de ser madre se había transformado en un crimen, incluso entre las casadas. La mujer recurría "a los más nefastos y anti-naturales recursos para evitar la concepción”. Así se violentaba y corrompía la naturaleza, lo que se traducía en el debilitamiento físico de la población. Pero este mal social, "fruto del refinamiento burgués", había invadido también a las clases más pobres, enseñándoles como era posible vivir y gozar "sin la carga maldita de los hijos". El editorial planteaba la necesidad de volver a los tiempos en que era "digna y elevada" la maternidad, lo que solo se conseguiría con la revolución, que regre-

101 Los textos citados aparecen mencionados, para la venta, en la contraportada de La mujer y la especie. No se encuentran en la Biblioteca Nacional. Algunos están disponibles en versión digital en el sitio "Proyecto de Filosofia en Español": http://www.filosofia.org/pcero.htm. En particular pueden consultarse el texto de Luis Bulffi: http://www.filosofia.org/aut/001/1909huvi.htm

102 "La familia" (Víctor Soto Román), en El Despertar de los Trabajadores, Iquique, 22/febrero/ 1913, 2. Sobre la polémica figura de Soto Román, véase el texto de Sergio Grez Toso, La alborada de “La Idea” en Chile. Los anarquistas y el movimiento obrero, 1893-1915 (inédito).

103 Los artículos estaban firmados por G. Hardy, pseudónimo de Gabriel Giroud, anarquista neomalthusiano, discípulo de Paul Robin. El Sembrador, Valparaíso, 20/nov./1926 y 15/enero/1927, cit. por Lavrín, Mujeres, 173-174 (el original no está disponible)

104 El Sembrador, Valparaíso, 20/nov./1926, 2, cit. por Lavrín, Mujeres, 174 (el original no está disponible). 
saría a la humanidad "al estado digno y puro que el capitalismo ha pretendido olvidar" 105 .

Como puede observarse, detrás del debate sobre el control de la natalidad no estaba en juego propiamente la defensa de los derechos del niño. Más bien se alineaban los defensores o detractores de la maternidad como una función irrenunciable de la mujer. De hecho, la principal argumentación de las políticas pronatalistas no estaba centrada en la valoración del niño, sino en el interés de la nación y el respeto a la naturaleza.

Más allá de la polémica, el uso de las técnicas contraceptivas estaba más extendido entre los sectores altos y medios, que en las clases populares. Así lo afirmaba el doctor Moisés Amaral, en una conferencia realizada en 1917, donde condenaba enérgicamente su uso. Para evitar que siguieran divulgándose, se excusó de dar detalles de los "numerosísimos" aparatos empleados por hombres y mujeres ${ }^{106}$

No obstante estos esfuerzos, el tamaño de las familias no se vio afectado y las tasas de natalidad siguieron permaneciendo estables, entre 38 y 41 por mil. Los cambios se producirían recién a partir de la década de $1960^{107}$.

Para la Iglesia, los hijos eran una bendición y no debía limitarse su número. Para el Estado, su política pronatalista quedaba garantizada a través de la promoción de la familia numerosa. Para la cultura popular, el embarazo era una consecuencia inevitable e impredecible. En palabras de Moisés Amaral, los pobres "ven llegar con la mayor calma la numerosa prole i dicen con musulmana resignación: "Los hijos son la herencia del pobre""108. Es probable que este ambiente fuera el más propicio para mantener alta la tasa de fecundidad. Sin embargo, si bien muchas madres y padres se resignaban ante la llegada de nuevos hijos, una cantidad difícil de precisar realizaba prácticas abortivas o incluso podía llegar al infanticidio.

Los textos referidos al aborto invariablemente descalificaban esta práctica, y lamentaban que en otros países se pretendiera legalizarlo bajo ciertas condiciones. Por entonces, efectivamente en Europa se discutía su legitimidad (para proteger la vida y la salud de la madre, en caso de embarazo por violación, etc.), tendencia que culminó en 1920 cuando se legalizó completamente en la Unión Soviética. En Chile no hubo cambios al respecto. Sin embargo, silenciosamente se practicaba, ya sea a través de técnicas quirúrgicas o bien de métodos artesanales que incluían el uso de yerbas. Incluso en la prensa se publicitaban pensionados de matronas que, prometiendo total reserva, ayudaban a las parturientas en sus primeros meses. Las autoridades amparaban la situación con su silencio. A pesar de las penas que establecía la legislación,

105 "Frutos de la indolencia", en La Federación Obrera, Santiago, 31/julio/1923, 1.

106 Moisés Amaral [Martínez], Los anticoncepcionales y el aborto criminal. Conferencia dada en la Sociedad Científica de Chile, en sesión de 28 de agosto de 1917, Santiago, Imprenta FrancoChilena, G. Gregoire, 1917, 6-9.

107 La tasa de mortalidad se mantuvo relativamente estable durante varias décadas. Aunque las estadísticas de fecundidad son más recientes, también pueden servir de referencia para medir la magnitud del cambio: la tasa global de fecundidad ha pasado de 5,4 hijos por mujer en edad fértil (15 a 49 años) en 1960 a 1,9 en 2003.

108 Amaral, Los anticoncepcionales, 8-9 
prácticamente los casos no llegaban a los tribunales. Cierto o no, circulaba la sensación de que la práctica del aborto iba en aumento ${ }^{109}$. Según las estadísticas que se manejaban, en promedio se practicaban 3.700 abortos al año en el país, aunque el doctor Isauro Torres calculaba unos 2 mil (del tipo "criminal") solo en Santiago. Torres era de opinión que el aborto era practicado tanto por las clases altas como por los sectores populares, aunque su incidencia era mayor en el primer grupo, por razones de "honor" y "moralidad" 110 . Algo similar opinaba el doctor Amaral, aunque su énfasis era mayor: los pobres acudían "rara vez" a maniobras abortivas"11.

La práctica del infanticidio también fue objeto de atención pública. A diferencia del aborto, penalizado pero tácitamente aceptado, el infanticio fue condenado de un modo más severo. Las penas que se aplicaban en la década de 1840 todavía contemplaban un ritual que simbolizaba la gravedad del crimen: el cadáver era colocado en un saco, junto a un animal (perro, gallo, culebra) para que le destrozara las entrañas y arrojado al río. Aunque esta práctica se eliminó con posterioridad, las sentencias condenatorias siguieron siendo numerosas, en comparación con el aborto. Cuando en 1874 se discutió la penalización del aborto y del infanticidio primó la idea de que ambas situaciones eran distintas para efectos de considerar las atenuantes. La ley debía proceder con más severidad contra los infanticidas ${ }^{112}$.

Entre los especialistas ha sido largo el debate sobre la magnitud del infanticio y del aborto. Para algunos fue una práctica generalizada antes del cristianismo, pero que logró ser contenida por motivos religiosos. Las evidencias no logran ser taxativas sobre el particular. Lo que parece claro, en cualquier caso, es que la condena moral se acrecentó. La tesis predominante es que, después del siglo XVIII, se generalizó la práctica del abandono, lo que disminuyó la importancia del aborto y el infanticidio ${ }^{113}$. A comienzos del siglo XX no se denunciaba que el infanticidio

109 Amaral, Los anticoncepcionales, 6; Adolfo Jofré Rossel, El delito del aborto, Santiago, memoria de prueba para optar al grado de licenciado en leyes y ciencias políticas de la Universidad de Chile, Imprenta Comercial, 1922, 3-5, 15-18 y 57-59; Luis Bórquez A., Estudio sobre el aborto, Santiago, memoria de prueba para optar al grado de licenciado en la Facultad de Leyes y Ciencias Políticas de la Universidad de Chile, Imprenta Comercial, 1922, 55-56; Fernando García Huidobro Domínguez, El aborto, Santiago, memoria de prueba para optar al grado de licenciado en la Facultad de Leyes y Ciencias Políticas de la Universidad de Chile, Imprenta y Librería Artes y Letras, 1925, 1115; Isauro Torres Cereceda, Mortinatalidad de Santiago (abortos i nacidos muertos), Santiago, tesis de Licenciatura en medicina, Clínica Universitaria de Obstetricia, Prof. Pardo Correa, Imprenta El Progreso, 1918, 37.

110 Según la información oficial en 1908 se realizaron 3.476 y en 1919 ya se registraban 3.914 . Bórquez A., Estudio sobre el aborto, 55. Los cálculos de Torres los realizó a partir de una proyección de $\operatorname{los}$ casos atendidos en la Maternidad $\mathrm{N}^{\circ}$ San Borja. Descartaba la utilidad de la información estadística oficial disponible. Torres, Mortinatalidad, 35-37.

111 Amaral, Los anticoncepcionales, 13.

112 Manuel Domínguez Larraín, El infanticidio desde el punto de vista penal y médico legal, Santiago, memoria de prueba para optar al grado de licenciado en la Facultad de Leyes y Ciencias Políticas, Soc. Impr. y Lit. Universo, 1923, 19, 32-33, 55-65 y 66. Jorge Ceardi Ferrer, El infanticidio bajo el punto de vista penal y médico legal, Valparaíso, memoria de prueba para optar al grado de licenciado en la Facultad de Leyes y Ciencias Políticas de la Universidad de Chile, Talleres Gráficos Proteo, 1926, 18-19.

113 René Salinas y Manuel Delgado, "Los hijos del vicio y del pecado. La mortalidad de los niños abandonados (1750-1930)", en Proposiciones, $N^{\circ} 19,1990,44-54$. 
fuera un fenómeno en expansión. En cambio, había preocupación por el abandono. Pero pronto se dejó de facilitar la recepción de niños en los orfanatos y en un corto período el fenómeno se contuvo. Calvo Mackenna estuvo detrás de esta reforma a partir de 1927, como hemos visto ${ }^{114}$.

\section{PALABRAS FINALES}

Aunque la difusión masiva de la doctrina de los derechos del niño es relativamente reciente, el concepto tiene un largo recorrido. Distintos enfoques han estado presente en los textos que circularon desde fines del siglo XIX y entre ellos no se observa una progresión, ya que algunos de los primeros documentos incorporaron miradas bastante radicales para la época, seguidos de otros más moderados.

No todas las declaraciones fueron conocidas en Chile. Las que alcanzaron mayor divulgación fueron la española de 1912, la de Ginebra de 1924 y la suscrita en Montevideo en 1927. Curiosamente el documento preparado por Gabriela Mistral en 1927 tuvo mayor divulgación en el resto de América Latina que en Chile.

En estos textos se proclamaba el derecho a vivir en condiciones materiales y sanitarias satisfactorias, recibir protección y cuidado, amor y consideración, educación elemental; incluso en algunos de ellos se enfatizaba el derecho a la alegría y la felicidad. Aunque no siempre hubo una referencia explícita, a veces se llegó a plantear que el Estado debía garantizar algunos de estos derechos.

En esta misma época hubo varias iniciativas que confluyeron en reconocer una mayor participación del Estado, sobre todo en materia sanitaria. Esto también se reflejó en la política laboral, que fue desplazando el tradicional enfoque liberal. De hecho, las primeras propuestas de regulación se concentraron sobre la situación de los niños trabajadores. En materia educacional, no solo se buscó ampliar la escolarización entre los sectores populares, sino que se acentuó la valoración de la libertad y la participación democrática en el proceso educativo. La filantropía privada, por su parte, contempló en forma creciente aspectos no materiales: la alegría, por ejemplo, debía unir a todos los niños, cualquiera fuera su condición social.

La referencia a los derechos del niño estuvo estrechamente ligada a la defensa de una experiencia material y espiritual que -se esperaba- una sociedad moderna debía garantizar a sus miembros más frágiles. Lograr que los niños alcanzaran un nivel máximo de felicidad (cuando a los adultos se les ofrecía un mínimo) pasó a ser un juicio relativamente extendido en los ambientes intelectuales y políticos en las primeras décadas del siglo. Regularmente, los parámetros para definir la felicidad del niño se consideraban reconocibles de un modo uniforme e inconfundible para todo espíritu moderno: acceso a alimentación, salud, aire libre, escuela, juegos y amor paterno. Solo de un modo excepcional se aceptaron ciertos niveles de autonomía en los niños, en particular para definir sus propios intereses. El espacio

114 BIIAPI, $\mathrm{N}^{\mathrm{o}} 1$ (t.II), julio/1928, 70-86. 
de la escuela fue el más sensible a este enfoque, aunque solo en asociación a ciertos proyectos pedagógicos, de alcance muy limitado.

En el período en estudio, aunque pocas veces se hizo alusión a los derechos del niño, surgió de un modo indirecto un cuestionamiento al consenso que muchos intelectuales percibían en torno a las necesidades de la infancia. Los ámbitos más polémicos fueron la religión y la política. Generalmente el debate se centró en cuestionar la influencia que ejercían en los niños, en un sentido u otro, católicos, masones y comunistas. Pocos concebían que fuera el propio niño el que pudiera optar por valores (morales, políticos y religiosos) que estaban por sobre él.

La doctrina de los derechos del niño, que dio sus primeros pasos en estas décadas, comenzó a demostrar un cierto sentido de excepcionalidad en su forma de justificar las garantías que debía asegurarle la sociedad a la población infantil. Lejos de asimilarlos a su condición "humana", igualando su estatus al del adulto (que por esos años luchaba para se le reconocieran derechos similares), acentuó el carácter peculiar que tenía el "ser niño" (por su fragilidad e inocencia) y su importancia estratégica para el futuro de la sociedad.

En la actualidad, los derechos del niño son vistos como la etapa culminante de un largo recorrido que evidencia la mayor preocupación y sensibilidad que ofrece nuestra sociedad hacia la infancia. Sin embargo, detrás de esta doctrina siguen sobreviviendo contradicciones, que no se alejan mucho de las que hemos observado. No hay gran debate sobre la necesidad de satisfacer ciertas necesidades materiales y afectivas. Pero sí lo hay en definir los límites de la autonomía o los mecanismos que permitan identificar el "interés superior del niño".

La exaltación de la infancia, que generalmente acompaña la defensa de sus derechos, suele concitar un artificioso consenso, que diluye los proyectos divergentes que surgen en muchas áreas del debate político. Algunos autores llegan a afirmar la existencia de una verdadera "ideología de la infancia", que logra crear sus propios mecanismos de legitimación en el plano valórico y se sitúa, con sospechosa comodidad, por encima de las contingencias, las estructuras socioeconómicas y los dilemas del desarrollo. Como si los niños solo se proyectaran en cuanto tales, y sus derechos fueran asimilables en su peculiar carácter de seres vulnerables, de no adultos, y se diluyeran al perder esa condición. 


\section{ANEXO: \\ Derechos del Niño, de José H. Figueira (1910)}

“1. El niño tiene derecho a ser bien nacido. Es decir, a ser sano y a ser hijo legítimo (Derecho eugenésico y moral).

“2. El niño tiene derecho a disponer de lo necesario para su desenvolvimiento completo y normal: alimento sano y suficiente, vestido limpio y apropiado, vivienda seca y alegre, con abundante aire, luz y sol. Una educación integral que progresivamente lo ponga en posesión de la herencia cultural de la raza en sus valores esenciales y duraderos (Derecho higiénico y cultural).

“3. El niño tiene derecho al cariño y a la protección de sus padres y al ejemplo moralizador del hogar.

“4. El niño tiene derecho a la libertad de su desenvolvimiento físico y mental. A realizar su propia vida para formar su carácter, su personalidad consciente, responsable y contribuir al progreso social. El único límite por ahora y mientras no se conozca mejor la naturaleza infantil, es prevenir, compensar, inhibir y en último término, reprimir toda manifestación perjudicial al individuo y a la sociedad.

“5. El niño tiene derecho a la recreación, al juego y a la alegría de vivir.

“6. El niño débil, física y mentalmente subnormal, así como el niño huérfano y abandonado, tiene derecho a la tutela y al cuidado de la comunidad y del Estado (Escuelas al aire libre, colonias de vacaciones, parques escolares, casa de reeducación, etc.

“7. El niño y el joven tiene derecho a una educación cultural y técnico-industrial, por lo menos hasta los 16 años de edad. Para ello a los 12 años de edad se comenzará por determinar las buenas aptitudes y habilidades vocacionales del joven, señalándole la escuela técnica o industrial que más le convenga.

“8. El niño tiene derecho de ser protegido contra toda explotación, contra todo mal tratamiento.

“9. El niño insubordinado o descarriado debe ser corregido y atendido de acuerdo con un sistema de reeducación médico-pedagógico especial.

“10. Todos los niños, sea cual fuere su raza y su condición social tienen los mismos derechos esenciales (Derecho natural de igualdad potencial)"115.

Declaración del Primer Congreso Español de Higiene Escolar, realizado en Barcelona (8-12 de abril de 1912).

"Habitantes de un planeta regido por el Sol, rodeado de atmósfera y cubierto de agua en dos terceras partes, corresponde de modo legislable a todos los niños:

115 El texto es citado por su hijo Gastón Figueira, en el artículo "José H. Figueira. Precursor de los derechos del niño", disponible en el sitio web http://www.perfiluruguayo.com/anoranzas_y.html Con ligeras variaciones es el mismo texto ("actualizado" por Figueira) que aparece citado en Asociación Popular Pro Cultura, Homenaje a la memoria de José H. Figueira (Montevideo Talleres Gráficos Goes, 1947), 15-17. 
“1. El derecho a la luz del Sol

"2. El derecho al aire abundante;

“3. El derecho al agua y a la limpieza que con ella se obtiene.

$\mathrm{Ni}$ el Estado, ni quienquiera que sea, tiene derecho para recluir al niño en locales cerrados a la luz y privados de agua y limpieza, por más que tales escondrijos se condecoren con el nombre de escuela o de inquilinato.

Por su condición de ser, en período de desarrollo el niño necesita alimento suficiente, ejercicio saludable, alegría que dilate su organismo, amor que fomente su vida moral, verdad que nutra su vida intelectual. Por eso tiene ineludiblemente:

"4. El derecho de sustento

"5. El derecho al ejercicio corporal

"6. El derecho a la alegría

"7. El derecho al amor

"8. El derecho a la verdad

Por eso es deber primario de la familia, y subsidiariamente del Estado, procurar la suficiente alimentación, la saludable recreación y alegría de los niños, a los cuales se debe la verdad y el amor.

Es crimen de la lesa niñez flagelar al niño o criarlo rodeado de tristeza.

El Código Penal debe castigar con prisión de uno a cinco años a quienquiera que golpee a un niño en la cabeza, sea con el puño (coscachos) o con reglas u otros instrumentos. Será circunstancia agravante que el golpeador sea el padre, preceptor o pariente del niño; y habrá acción popular para denunciar este delito. Lastimar el cerebro de un niño es preparar un ciudadano negativo, esto es un criminal o un idiota, que será más o menos idiota según sea la gravedad de la lesión que se le inflija en el golpe.

Enseñar a un niño la mentira, con cualquier traje que se disfrace, es crimen de lesa humanidad"116.

Declaración de Ginebra, suscrita por la Sociedad de las Naciones, 26 de septiembre de 1924

"A fin de que los Gobiernos, los hombres y las mujeres de todas las naciones reconozcan que la Humanidad debe conceder al Niño cuanto estime mejor y más beneficioso para él y sustentar como sus deberes, excluida toda consideración de raza, nacionalidad o creencia religiosa, se declara:

“I. El Niño debe ser puesto en condiciones de realizar normalmente su desarrollo físico y espiritual

“II. El Niño hambriento debe ser alimentado; el Niño enfermo debe ser asistido; el Niño retrasado en su educación debe ser alentado a proseguirla; el Niño

116 La revista azul, $\mathrm{N}^{\circ} 1$, noviembre/1914, 20. 
desviado de la buena senda debe ser vuelto a ella; el huérfano y el abandonado deben ser recogidos y socorridos.

“III. El Niño debe ser el primero en recibir socorro en toda ocasión de calamidad pública.

"IV. El Niño debe ser puesto en condición de ganar la subsistencia y ser protegido contra toda clase de explotación.

"V. El Niño debe ser educado inculcándole el sentimiento del deber que tiene de poner sus mejores cualidades al servicio de sus hermanos"117.

Decálogo de los Derechos del Niño, suscrito en Montevideo, 9 de junio de 1927

“Tabla de los Derechos del Niño en cuya observancia reposa el progreso de los pueblos:

“1. Derecho a la vida. Suma de todos los derechos por la sola razón de haber nacido. Derecho a la casa para habitar, a la atención materna, al reconocimiento obligatorio por el padre, con todos los deberes que la paternidad impone, a la supervigilancia del Estado para su desarrollo y prosperidad fisiológica.

“2. Derecho a la educación. Primera asistencia a los Jardines de Niños, Kindergarten. Segundo ciclo: escuela primaria. Abolición del sistema de escuelas de ciudad. Abolición de la enseñanza verbalista y libresca. Reintegración del niño al seno de la naturaleza, por medio de una escuela de actividad, de trabajo, de alegría, Parques Escolares, para lograr las reacciones de cuerpo y alma, salud, inteligencia y emoción, y preparar los obreros de su propio destino y de la grandeza social.

“3. Derecho a la educación especializada. Escuelas de salud, al aire libre, de bosque, de pradera, de escuelas al sol, para los anormales, los tarados, los enfermos, los débiles.

“4. Derecho a mantener y desarrollar la propia personalidad. Estudio de las vocaciones, sistemas capaces de la orientación espiritual sin artificios, que solo puede lograrse en los Parques Escolares, en la vuelta a la naturaleza, por reacción de lo íntimo frente a la vida exterior. Reconocimiento, en la práctica de los sistemas educacionales, del derecho a ser niño, de vivir y sentir como tal, libre de la fría artificialidad de la escuela-claustro y del dogma pedagógico que la informa.

“5. Derecho a la nutrición completa. Derecho de la madre a criar a su hijo. Seguro del Estado para las madres sin recursos. Servicios de gota de leche. Instalación de merenderos escolares. Instalación de Escuelas-Refectorios para menores que trabajan antes del cumplimiento integral de esta tabla de Derechos.

“6. Derecho a la asistencia económica completa. Este derecho significa la obligatoriedad de los padres, o en su defecto del Estado, a asegurar al niño la

117 Transcribimos el texto publicado en Antecedentes, actas y trabajos del Cuarto Congreso Panamericano del niño, celebrado en Santiago de Chile en el Palacio del Congreso Nacional, los días 12 a 19 de octubre de 1924, Santiago, Imprenta Cervantes, 1925, t. I, 148-149. 
situación económica sin angustias. Derecho a la vivienda, al vestido, a todas las oportunidades de bienestar que el trabajo del hombre pone al servicio del progreso del mundo.

“7. Derecho a la Tierra. Tierra para habitar. Reconocimiento del derecho del niño a ocupar su lugar en el mundo, por la sola razón de haber nacido. Tierra para trabajar puesta a su alcance en los Parques Escolares, para el desarrollo de sus energías, de su impulso vital, de su inquietud, de sus facultades de observación, para aprender por sí mismos en el vasto panorama del universo y comprender que la vida es una ley inmutable de solidaridad en el esfuerzo creador.

“8. Derecho a la consideración social. Todo para el niño. Abolición de la distinción jurídica entre hijos legítimos e hijos naturales. El hijo es solamente hijo. El niño tiene derecho a sus padres. Transformación de los asilos de huérfanos y reformatorios de menores, donde el sistema de "Pabellón" anula la personalidad, en colonias familiares, de educación y de trabajo, organizadas en pequeños núcleos sociales y confiadas a padre y madre que sumen al afecto de sus hijos el de un pequeño grupo de niños sin hogar.

“9. Derecho a la alegría. Reconocimiento sin retaceos de este derecho, en la vida familiar sin angustia económica, en la escuela activa en el seno de la naturaleza, en la educación sin artificios, en la mesa con pan, en el hogar con lumbre. Derecho al aire y la luz, a la tierra en que se siembra, al fuego que calienta y al agua que purifica. Derecho a ser niño para ser hombre, a formar con cuerpo sano y alma limpia los obreros de la libertad, los arquitectos de la conciencia del mundo.

“10. La suma de estos derechos del niño forma el derecho integral: derecho a la vida. De su reconocimiento y su observancia depende la grandeza de los pueblos. En la salud, la alegría, la formación sin trabas de los niños para la cultura, para el trabajo, para la libertad y la cooperación reposan los valores del destino del hombre en una etapa nueva de la Historia"118.

118 El texto completo está transcrito en BIIAPI, No 1, julio/1927, 39-41. 
